\title{
Experimental Constraints on Homogenization of Plagioclase-Hosted Melt Inclusions From Plagioclase Ultraphyric Basalts
}

\author{
Kristen R. Lewis ${ }^{1}$, Gokce K. Ustunisik ${ }^{1,2 *}$ and Roger L. Nielsen ${ }^{1,3}$ \\ ${ }^{1}$ Department of Geology and Geological Engineering, South Dakota School of Mines and Technology, Rapid City, SD, \\ United States, ${ }^{2}$ Department of Earth and Planetary Sciences, American Museum of Natural History, New York, NY, United States, \\ ${ }^{3}$ College of Earth, Ocean, and Atmospheric Sciences, Oregon State University, Corvallis, OR, United States
}

\section{OPEN ACCESS}

Edited by:

Marc-Antoine Longpré, Queens College (CUNY),

United States

Reviewed by: Takeshi Kuritani, Hokkaido University, Japan

Jason Peter Coumans, Durham University, United Kingdom

*Correspondence:

Gokce K. Ustunisik Gokce.Ustunisik@sdsmt.edu

\section{Specialty section: \\ This article was submitted to Petrology, \\ a section of the journal \\ Frontiers in Earth Science}

Received: 17 July 2020 Accepted: 04 December 2020 Published: 15 January 2021

Citation: Lewis KR, Ustunisik GK and Nielsen RL (2021) Experimental Constraints on Homogenization of PlagioclaseHosted Melt Inclusions From Plagioclase Ultraphyric Basalts. Front. Earth Sci. 8:584371. doi: 10.3389/feart.2020.584371
Study of melt inclusions (Mls) is a commonly applied method for defining the composition of magmas present at depth prior to mixing, fractionation, and degassing. Our ability to use data from Mls is complicated by post-entrapment processes (PEP) that can modify their composition during transport and eruption. Many of the PEP can be reversed by heating the Mls to temperatures near those at which the Ml and its host were formed. However, the process of reversing PEP by homogenization may introduce changes in Ml compositions, making interpretation difficult. We present a series of low and high pressure homogenization experiments on plagioclase-hosted Mls from Plagioclase Ultraphyric Basalts (PUBs) designed to develop a methodology for recovering the composition at the time of entrapment of plagioclase-hosted Mls. These experiments included low pressure (1 bar) homogenization experiments conducted as a time series for $30 \mathrm{~min}$, $4 \mathrm{~h}, 1$ day, 4 days, and 8 days), and at $7.5 \mathrm{kbar}$ for 2 and 4 days. The $7.5 \mathrm{kbar}$ pressure used for the high pressure experiments was based on the $\mathrm{CO}_{2}$-based entrapment pressures determined from $\mathrm{Ml}$ from this sample. Experiments run at low pressure and run times of 4 and 8 days exhibited compositional drift, most notably in the form of increasing $\mathrm{MgO}$ in Mls. This drift was not observed at $7.5 \mathrm{kbars}$ or for the shorter run time $1 \mathrm{~atm}$ experiments. These results are consistent with a model where drift in composition with time is caused by crystal relaxation driven by the high internal pressure within the Ml (the pressure at which the $\mathrm{Ml}$ formed), together with the lower confining pressure during homogenization (1 bar). Therefore, MI homogenization will produce the least amount of drift if runs are made for short time periods ( $30 \mathrm{~min})$ or at the pressure of entrapment.

Keywords: PUBs, Plagioclase, melt inclusions, MORB, trace elements

\section{INTRODUCTION}

Mid-ocean ridge basalts (MORBs) are frequently used as proxies for understanding the physical and chemical characteristics of the mantle as well as developing models for the formation of oceanic crust. However, as magmas are transported from the site of generation to eruption, multiple processes modify their physical and chemical characteristics (Coogan, 2014). These processes include fractionation, magma mixing/mingling, assimilation, and degassing (Maclennan, 2008; Rubin et al., 2009; Shorttle et al., 2015). Therefore, the lavas erupted on the seafloor may no longer be 
representative of the melts initially derived from the mantle (O'Hara, 1977; Langmuir, 1989; Michael and Shilling, 1989; Lissenberg and Macleod, 2016; O’Neill and Jenner, 2016).

One method commonly used to define the characteristics of the array of primitive melt compositions that existed prior to and during mixing, degassing, and fractionation is the study of melt inclusions (MIs) trapped in early crystallizing phases (Kohut and Nielsen, 2004; Kent and Putirka, 2008). In general, it is assumed that MIs are closed systems, in that they preserve geochemical information of the magmas at the time of entrapment. Under ideal circumstances, crystals forming from a suite of magmas will trap the suite of evolving liquids as they undergo processes such as mixing, fractionation, and degassing during storage and their transport to the surface. However, during transport, storage, and eruption, MIs undergo post-entrapment modification such as crystallization or diffusive re-equilibration (Danyuschevsky et al., 2002; Kent and Putirka, 2008). Here we use post-entrapment crystallization as a term that includes both the formation of daughter crystals within the MI as well as host growth at the crystal melt interface (Tait, 1992; Danyuschevsky et al., 2002). In many cases, MIs require homogenization to remove the postentrapment crystals, and that homogenization process also can affect the composition of MIs (Schiavi et al., 2016; Drignon et al., 2019). This is particularly true of plagioclase megacrysts in plagioclase ultraphyric basalts (PUBs) that are carried to the surface in magmas that are significantly more evolved than the magmas from which anorthitic megacrysts form (Lange et al., 2013a; Lange et al., 2013b). This results in up to $100^{\circ} \mathrm{C}$ undercooling and thus pervasive post-entrapment crystallization prior to eruption. Nevertheless, the primitive character of those megacrysts and their MIs make such crystals a fertile source of otherwise unobtainable information on magma diversity and volatile contents.

Post-entrapment processes affect the evolution of the MI composition and cause the MI to deviate from the melt composition at the time of entrapment. It is important to note that homogenization parameters are determined differently for plagioclase-hosted MIs as compared to olivine-hosted ones. Olivine-hosted MIs are often heated using a heating stage and homogenization temperature is determined by the disappearance of the vapor bubble (Danyushevsky et al., 2000; Danyushevsky et al., 2002). Vapor bubbles may be present due to relaxation of the host and may persist through heating. Thus, using the vapor bubble as a means to determine the homogenization temperature has been documented as an imprecise method. In addition, changes in the crystal as a function of heating time can cause the homogenization temperature to differ from the entrapment temperature (Schiavi et al., 2016; Drignon et al., 2019).

Plagioclase-hosted MIs have an additional constraint due to the fact that primitive MIs are saturated with both plagioclase and olivine (plagioclase-olivine cotectic) (Bryan, 1983; Nielsen, 2011). As such, we can apply calculated phase equilibria (e.g. MELTs Ghiorso et al., 2002), the presence of olivine daughter crystals, and the assumption that the liquids are on the plagioclase-olivine cotectic to determine the homogenization parameters rather than the temperature at which the vapor bubble disappears (Roedder, 1979; Sinton et al., 1993; Nielsen, 2011). Additionally, post- entrapment processes can be dealt with computationally by adding or subtracting the composition of the host crystal. However, primitive plagioclase-hosted MIs contain multiple phases (olivine, plagioclase) which do not grow in cotectic proportions thus making computation difficult (Danyushevsky et al., 2002; Lange et al., 2013a; Lange et al., 2013b; Neave et al., 2017). To apply this method, one needs to know the precise compositions of the daughter crystals, which are often too small to analyze.

To see through the effects of post-entrapment and homogenization processes, we must understand how constraints such as duration of heating and pressure used during the homogenization process, could modify the composition of MIs and/or host mineral. This question therefore has at least three parts. First, one needs to understand the characteristics of the post-entrapment modification that happens prior to quench. Second, if we want to use homogenization to recreate the melt at the time of entrapment, we need an independent measure for what to expect (e.g. what does successful homogenization look like). Finally, we need to understand what happens to both the physical characteristics and composition of both MI and its host during homogenization. To the first order, heating provides the conditions where the post-entrapment crystals are incorporated back into the MI therefore producing a homogenous glass that represents the melt at the time of entrapment. The temperature and pressure at which the inclusions are homogenized should be those of MI entrapment (Nielsen, 2011). Therefore, experimental conditions for homogenization are based on the observed phase equilibria (Nielsen, 2011) and the volatile abundances contained within the MIs, which together can be used to calculate the temperature and pressure of entrapment (Ghiorso and Gualda, 2015). However, there is evidence that heating at pressures that are not that of entrapment can cause changes in the mineral structure and melt composition (Schiavi et al., 2016; Drignon et al., 2019).

The goal of this research is to understand how sensitive melt inclusion compositions are to the temperature, pressure, and time of homogenization and develop a methodology to recreate the melt composition at the time of entrapment. Constraining the major, trace, and volatile element characteristics within the MI compositions as a function of temperature, pressure, and time will also help to better understand the nature of processes that modified the initial melt composition en route to the surface.

We focused this work on experimentally heating plagioclase megacrysts from plagioclase ultraphyric basalts (PUBs), a component of the array of MORB lavas. PUBs are characterized by abundant $(>15 \%)$, large $(\sim 2 \mathrm{~mm}-2 \mathrm{~cm})$ plagioclase megacrysts with a high anorthite content $\left(\mathrm{An}_{80-94}\right)$ (Lange et al., 2013a; Lange et al., 2013b). Based on their texture and composition, these anorthitic feldspars are not in equilibrium with the host glass (Kohut and Nielsen, 2004). Their high and relatively narrow range of anorthitic content and wide range of trace element composition suggests that they formed prior to fractionation and mixing, and therefore are a means for improving our understanding of the magmas formed in the mantle. The fact that these anorthitic megacrysts are large and 
comparatively easy to work with, have abundant MIs, and have been well characterized in a number of previous studies (Sinton et al., 1993; Nielsen et al., 1995; Lange et al., 2013a; Lange et al., 2013b; Drignon et al., 2019) help us to set boundary conditions for this work (e.g. pressure of entrapment, range of An content, constraints on homogenization temperature).

\section{BACKGROUND}

\section{Melt Inclusions as Proxies}

Melt inclusions have been studied as a source of geochemical information on primitive melts for over 40 years (e.g. Anderson and Wright, 1972; Dungan and Rhodes, 1978; Roedder, 1979; Sobolev and Shimizu, 1993; Sobolev, 1996). However, it was the development of micro-analytical tools (e.g., Secondary Ion Mass Spectrometry-SIMS) capable of analyzing trace elements in MIs and their adjacent hosts that enabled the increased attention to and application of MI data. A further increase in interest in MIs resulted from additional technical developments in microanalysis, as well as improved understanding of the solubility of volatiles as a function of temperature, pressure, and composition (Kent and Putirka, 2008; Ghiorso and Gualda, 2015).

Most of the existing MI research on basaltic systems focuses on olivine-hosted MIs (Sobolev and Shimizu, 1993; Wanless and Shaw, 2012; Le Voyer et al., 2017). The rationale for a focus on olivine is that it is perceived to be the first mineral to crystalize from basaltic magmas and are therefore a source of information on the character of magmas early in the evolution of a suite of magmas. Further, olivine-hosted MIs have been preferred over plagioclase because it is thought plagioclase-hosted MIs are susceptible to leakage along cleavage planes. However, the recent work by Drignon et al. (2018), Drignon et al. (2019) has shown that $\mathrm{CO}_{2}$ does not diffuse through plagioclase on the timescale of days. Diffusion of $\mathrm{H}$ out of plagioclase-hosted MIs is significant and occurs on the timescale of hours (Gaetani et al., 2012). Nevertheless, the rate of $\mathrm{H}$ loss is much slower than is the case for olivine-hosted MIs, that occurs in less than an hour at temperatures near $\sim 1,250^{\circ} \mathrm{C}$ (Gaetani et al., 2012; Ferris et al., 2018). Therefore, plagioclase-hosted MIs are an important additional source of data on the chemical characteristics and the depth of formation of primitive MORB magmas (Drignon et al., 2018). Additionally, plagioclase is an abundant host that can be found in magmas ranging from basalt to rhyolite, whereas olivine is commonly restricted to basalts.

Volatile $\left(\mathrm{CO}_{2}\right.$ and $\left.\mathrm{H}_{2} \mathrm{O}\right)$ contents measured from MIs can be used to estimate the pressure and therefore depth of plagioclase formation (Ghiorso and Gualda, 2015; Coumans et al., 2016). Establishing the pressure of entrapment is essential for experimental homogenization. Drignon et al. (2018) reported crystallization pressures between 2.3 and $9.1 \mathrm{kbars}$, with the majority between 3 and $7 \mathrm{kbars}$, for plagioclase megacrysts from PUBs sampled from the Blanco Fracture Zone. Each of those pressure estimates have errors of $\sim 1.5 \mathrm{kbar}$ and are as high or higher than the pressure estimates based on data from olivinehosted MIs from other ocean floor basalts (Bennett et al., 2019;
Kotash et al., 2019). An understanding of the range of values requires an accurate estimate for the total $\mathrm{CO}_{2}$ content of MIs. In turn, the $\mathrm{CO}_{2}$ estimate is subject to knowledge of the homogenization parameters such as heating rate and run time, as well as the details of how $\mathrm{CO}_{2}$ is distributed in the MI.

Drignon et al. (2019) reported the results of a series of homogenization experiments run on plagioclase megacrysts from PUBS samples from the Blanco Fracture Zone. Experimental run times were $30 \mathrm{~min}, 4 \mathrm{~h}, 1$ day, and 4 days. They observed a systematic drift in the melt inclusion $\mathrm{MgO}$ composition with time, which was attributed to crystal deformation/relaxation and pressure loss within the MI. During homogenization at $1 \mathrm{bar}$, the internal pressure of the MI drops in response to the deformation of the host crystal (Schiavi et al., 2016). It is thought that host deformation is a plastic process, as MIs and vapor bubbles grow with heating and do not return to their original size with cooling (Danyushevsky et al., 2000, Danyushevsky et al., 2002). Deformation of the crystal occurs when the internal pressure within the MI (which begins at the pressure of entrapment) pushes outward on the crystal at the same time as heating at 1 bar (reduced confining pressure) allows the crystal to respond to lower internal pressure in the MI (Schiavi et al., 2016). In effect, plagioclase deforms as it "relaxes" in order to eliminate the pressure differential between the MI and the confining pressure on the host. The compositional drift of melt inclusion $\mathrm{MgO}$ with experimental heating time reported by Drignon et al. (2019) was attributed to a drop in the $\mathrm{Mg}$ plagioclase/melt partition coefficient during homogenization that could be related to a drop in pressure. However, the partitioning database for $\mathrm{Mg}$ plagioclase/melt partitioning is insufficiently precise to affirm that the $\mathrm{Mg}$ partition coefficient is pressure or temperature dependent (Nielsen et al., 2017). In addition, even if our understanding of the compositional, temperature, and pressure dependence of $\mathrm{Mg}$ partitioning between plagioclase and melt were more precise, we must recognize that equilibrium is rarely achieved during the process of MI homogenization. Within the timeframe of such experiments, the crystal will continue to deform, the internal pressure will change, and diffusive exchange will move towards equilibrium, which is a moving target. In the face of the documented change in melt inclusion $\mathrm{MgO}$ content as a function of time, it is important for us to understand if other elements behave similarly, and if the observed trends are dependent on MI or host composition. This knowledge is required if we are to understand the geochemical signals evident in plagioclase-hosted MIs, particularly the heterogeneity of their trace element signal (Lange et al., 2013a; Lange et al., 2013b; Nielsen et al., 2020).

To understand how the composition within and around the MI change during homogenization, we conducted a series of experiments that expand on the work of Drignon et al. (2019). The objective of this new research is to answer the question: Does confining pressure influence the major and trace element partitioning behavior between the plagioclase host and its MIs? In effect, we expanded the scope of the previous research to include the behavior of trace elements, different host compositions and experimental confining pressure. 


\section{We Tested Two Scenarios}

(1) Assuming equilibrium at the time of entrapment, the progressive diffusive exchange of major and trace components between the host plagioclase and the MI is caused by crystal relaxation and resultant reduction in pressure within the MI.

(2) Host plagioclase and MIs are not in equilibrium at the time of entrapment. During the heating process, the crystal and MI are driven towards equilibrium, and produce the compositional profiles seen at the $\mathrm{MI} /$ host interface.

Before we experimentally test which scenario describes the driving forces for compositional drift, we will describe some of the boundary conditions and terminology we will be applying.

\section{Crystal Relaxation}

For the purpose of this investigation, we will use the term "crystal relaxation" for the phenomenon where the crystal deforms in response to the pressure differential between the pressurized MI, and the host crystal or in response to lower confining pressure. As previously noted, it is thought that the plagioclase host deformation is plastic (Danyushevsky et al., 2002). The degree to which the MI and surrounding host composition responds to the relaxation is unknown, as well as the driving mechanism (e.g. changes in partition coefficients, diffusion rate, etc.). The utility of MIs as a source of information on evolving magma suites is based on the assumption that they preserve melt compositions unmodified by late stage process such as fractionation or mixing, as well as preserve information about temperature and pressure of formation. This assumption is only true if post-entrapment processes can be reversed and the MI remains isolated from the rest of the melt and is not significantly modified by reaction with the host crystal (e.g. diffusive exchange). For example, if a MI is breached, it is no longer a closed system and cannot be interpreted as such. Although MIs undergo compositional changes during magma ascent and crystallization due to post-entrapment processes, it has been presumed that decompression and resultant physical deformation of the host is minimal (Zhang, 1998).

Schiavi et al. (2016) conducted experiments on olivinehosted MIs to determine pressure, temperature, and volume (of the inclusion) constraints on MI homogenization. These experiments documented that homogenization at $1 \mathrm{bar}$ results in an increase in the volume of the MI due to deformation of the host crystal. This deformation was inferred to occur as a result of the pressure differential between the MI and the host. During reheating, the host crystal relaxes in response to pressure re-equilibration between itself and the initially pressurized MI (Danyushevsky et al., 2002; Schiavi et al., 2016; Drignon et al., 2019). Schiavi et al. (2016) suggested that the method for avoiding crystal relaxation is to apply external pressure to the crystal host during homogenization.

\section{Entrapment Under Disequilibrium Conditions}

Trace element analysis taken from core to rim of plagioclase crystals from PUBs were studied by previous researchers to investigate melt evolution. These analyses yielded no progressive trend (e.g. normal or reverse zoning-Adams et al., 2011; Nielsen et al., 2020). This suggests that the plagioclase megacrysts formed from a series of different liquids that were not linked by any simple mixing or fractionation process. Although the major element variation is minimal in comparison to trace element variation, rejuvenation events (new magma pulses), different magma sources, or magma mixing/ mingling are consistent with the observed range of composition. The lack of correlation of major and trace element signatures throughout the growth of the crystals supports the conclusions of Lange et al. (2013a), Lange et al. (2013b) that the plagioclase megacrysts formed via sidewall crystallization within conduits that transported magma from the mantle to the ocean floor. Therefore, it is possible that melt trapped as inclusions during plagioclase growth is not representative of the initial magma, but rather different magmas that the crystal has come into contact with, depending on when entrapment occurred. Kohut and Nielsen (2004) demonstrated that, for a system similar to the one we investigated the rate of diffusion in the melt is typically, but not always, faster than the rate of crystal growth related to MI formation. If the melt trapped as a MI came from a different magma source (for example following a mixing related rapid crystallization event), the extent of disequilibrium between the host plagioclase and the MI must be assessed if we are to use MI information to understand processes active in the regions where the anorthitic megacrysts form. This approach was applied to evaluate host/MI equilibria by Nielsen et al. (2017), who reported that the ratio of the concentration in the host to that in the homogenized MI was within error of the experimentally determined partition coefficients for those elements. However, those comparisons were made for MI that had been homogenized for $30 \mathrm{~min}$.

\section{EXPERIMENTAL PROCEDURES}

\section{Experimental Design}

We designed a set of homogenization (heating and subsequent quenching) experiments at $1 \mathrm{bar}$ and $7.5 \mathrm{kbars}$ completed in the form of a time series ( $30 \mathrm{~min}, 4 \mathrm{~h}, 1$ day, 4 days, and 8 days) to evaluate the effect of confining pressure and the duration of heating on MI composition. We analyzed major and trace element compositions for both low and high pressure experiments to measure differences that could be tied to whether or not confining pressure has an effect on the MI and host plagioclase composition. 1 bar represents the surface pressure, while $7.5 \mathrm{kbars}$ was chosen because it represents a pressure near the maximum of the calculated pressure of plagioclase crystallization based on $\mathrm{MI} \mathrm{CO}_{2}$, which represent minimum entrapment pressures (Drignon et al., 2018). 


\section{Sample Selection and Characteristics}

Two PUB samples, D23-2 from the West Valley of the Juan de Fuca Ridge and A91-1R1 from the Blanco Fracture Zone (BFZ) were selected for this study. In addition to being characterized by high phenocryst content ( $>20 \%$ in both cases), the crystal cargo of each was characterized by a relatively narrow range of anorthite content as well as average anorthite contents that were distinctly different from one another (A91-1R1: $84 \pm 2 \%$; D23-2: $88 \pm 2 \%$ ). The $\sim 4 \%$ An difference between the average megacryst composition was judged to be sufficiently large that we could use any differences in the results to evaluate the role of host composition. It is important to note that the total range of anorthite content in PUBs is 86-92\% (Lange et al., 2013a; Lange et al., 2013b).

Plagioclase megacrysts were extracted from each sample by crushing and hand picking. Sample A91-1R1 was the same sample that was the subject of Drignon et al. (2019) where the drift of $\mathrm{MgO}$ within $\mathrm{MI}$ as a function of heating time was first identified. The melt inclusions hosted within the plagioclase megacrysts range in radius from 2 to $>100 \mu \mathrm{m}$. Plagioclasehosted MIs tend to have tabular or disc-shaped morphology with two long axes and one shorter axis. Prior to homogenization they are characterized by side-wall post-entrapment crystallization at the MI-plagioclase interface and by minute daughter crystals (plagioclase and olivine) within the MI as well as a vapor bubble (Drignon et al., 2019). These samples were chosen in part due to the fact that the MIs exhibit a relatively narrow range of major element compositions associated with comparatively heterogeneous trace element composition in the plagioclase host and MI within each sample (Nielsen, 2011; Lange et al., 2013a; Lange et al., 2013b; Nielsen et al., 2020). However, these are natural samples, thus there is some initial variability in post-entrapment crystallization prior to homogenization.

\section{Experimental Details}

\section{Low Pressure Homogenization Experiments}

Low pressure homogenization experiments were conducted at 1 bar using the vertical quench furnace at South Dakota School of Mines and Technology (SDSM\&T). Experiments were performed in air without measurement of $\mathrm{fO}_{2}$. This decision was based on previous work that determined $\mathrm{fO}_{2}$ to be near Fayalite-MagnetiteQuartz buffer (FMQ), as well as the fact that oxygen does not diffuse through feldspar at the timescale of these experiments (Drignon et al., 2019; Dygert et al., 2020). The entrapment temperature of $1,230^{\circ} \mathrm{C}$ was determined using observation of batches of MIs heated sequentially (as per Nielsen et al., 1995). In detail, batches of crystals were heated to temperatures just below our estimate of the entrapment temperature and examined for presence of daughter crystals and the degree to which the MI lay at or near the olivineplagioclase cotectic. If daughter crystals or sidewall crystals were present in the MI, another batch of crystals were heated to a temperature $10^{\circ} \mathrm{C}$ above the initial batch. This process was continued until the MI compositions departed from the olivineplagioclase cotectic on to a plagioclase control line. These temperatures were then confirmed by heating stage (Lange et al., 2013a; Lange et al., 2013b; Drignon et al., 2019).
Depending on the size of the megacryst up to six crystals were placed in Pt-foil boats wrapped in fine Pt-quench wire (0.003 inches) and suspended from a thicker Pt-suspension wire $(0.024$ inches). The run assembly was then lowered into the furnace to the hot spot at $1,230^{\circ} \mathrm{C}$ for the duration of each experiment. At the end of designated times the sample was quenched by running an electric current through the Ptquench wire causing it to vaporize. This allowed the boat containing the sample to drop into water in the quench chamber. For plagioclase-hosted inclusions, this rapid quench is necessary because crystallization within the MI can happen even during the removal of the assembly from the furnace if the sample is quenched in air. Previous work showed that 3-5 s between the removal of the run assembly from the furnace and quench could cause percent level changes in the $\mathrm{Al}$ and $\mathrm{Ca}$ concentrations of the MI (Nielsen et al., 1995). Following the homogenization experiments, probe sections were prepared by exposing the MIs at the surface of before the final polish.

It is important to note here that a major advantage of a vertical quench furnace is the minimal sample preparation required before the experiments are run. One needs only separate crystals from the host and place them in a Pt-foil boat. Up to six crystals can be run at a time, then examined to evaluate the degree to which the effects of post-entrapment crystallization had been reversed. Crystals that did not satisfy those conditions (e.g. remaining daughter crystals at low temperature end to liquids on a plagioclase alone control line) were eliminated from further study. Note that plagioclase control line refers to the process vector describing addition or subtraction of plagioclase to the melt.

\section{High Pressure Homogenization Experiments}

High pressure homogenization experiments were conducted using an end-loaded piston-cylinder apparatus at Lamont-Doherty Earth Observatory (LDEO). End loads of 150 tons were applied to the $1 / 2^{\prime \prime}$ pressure vessel of BoydEngland design. Piston loading by a $3^{\prime \prime}$ ram to reach $5 \mathrm{kbar}$ of 198 bars oil pressure used the calibration for $\mathrm{BaCO}_{3}$ of Fram and Longhi (1992). Experiments were run at $7.5 \mathrm{kbar}$ and $1275^{\circ} \mathrm{C}$ for run times of 2 and 4 days. The temperature for high pressure runs was based on the results of a set of phase equilibria experiments on PUB compositions (Ustunisik et al., 2020). Similar to low pressure experiments, $\mathrm{fO}_{2}$ was not measured on the assumption that oxygen does not diffuse any quicker at high pressure than it does at low pressure.

Runs were performed in a $1 / 2$ inch $\left({ }^{\prime \prime}\right)$ inside diameter BoydEngland compound pressure vessel with cylindrical $\mathrm{Pb}$-wrapped $\mathrm{BaCO}_{3} / \mathrm{MgO}$ pressure medium $\left(0.487^{\prime \prime}, 0.313^{\prime \prime}, 1.25^{\prime \prime}\right)$, graphite furnace $\left(0.312^{\prime \prime}, 0.25^{\prime \prime}, 1.25^{\prime \prime}\right)$, high-density $\mathrm{Al}_{2} \mathrm{O}_{3}$ sleeve $\left(0.248^{\prime \prime}\right.$, $\left.0.181^{\prime \prime}, 0.25^{\prime \prime}\right)$, one-hole and solid $\mathrm{MgO}$ spacers $\left(0.5^{\prime \prime}\right), \mathrm{MgO}$ wafer $\left(0.078^{\prime \prime}\right)$, and platinum capsule, with continuous external $\mathrm{H}_{2}-\mathrm{N}_{2}\left(5 \% \mathrm{H}_{2}, 95 \% \mathrm{~N}_{2}\right)$ flow to protect the thermocouple from oxidation.

Plagioclase phenocrysts (2-3 depending on size) were loaded in platinum capsules packed with cesium iodide, which is compressible therefore avoiding the destruction of crystals. Experiments were pressurized cold then heated incrementally 
to $850^{\circ} \mathrm{C}$ for over an hour after which the assembly was left at $850^{\circ} \mathrm{C}$ overnight to stabilize and close porosity in the pressure media. After repressurization, temperature was raised in $50^{\circ} \mathrm{C}$ steps of approximately $20 \mathrm{~min}$ to the run temperature, repressurized after $20 \mathrm{~min}$, left for the experiment duration and quenched by turning off the electric power. Cooling to less than $400^{\circ} \mathrm{C}$ took approximately $5 \mathrm{~s}$. Run products were mounted in epoxy then sectioned and polished for petrographic and geochemical analysis.

\section{ANALYTICAL TECHNIQUES}

\section{Electron Microprobe Analysis}

Backscattered electron (BSE) images and major element abundances for plagioclase and glass from the experimental runs were obtained using the Cameca SX100 electron microprobe (EMP) at Oregon State University (OSU). BSE images were used to map out the location and size of each melt inclusion analyzed.

Major element data were obtained both as point analysis of MIs and traverses from the plagioclase host into individual MIs. The criteria used to determine if MI were breached were based on the findings of Nielsen et al. (1995), Nielsen et al. (1998) with a focus on the MI morphology and the sulfur content. In their findings, breached or decrepitated MIs lost all of their sulfur in less than $30 \mathrm{~min}$ heating time. MIs that fell off the sulfur saturation curve by $2 \sigma$ were considered breached and therefore discarded based on the assumption that MORB lavas are sulfide saturated (Wallace and Carmichael, 1992; Nielsen et al., 1998; Drignon et al., 2019). Point analysis were done at the center of the MI in order avoid overlap with the host plagioclase. Traverses were taken from the plagioclase host to the MI with a step size of $2 \mu \mathrm{m}$. Traverses also approached the MI from different directions in order to address the possibility of diffusional anisotropy, whether diffusion profiles vary or not along different crystallographic axes.

Calibration for glass was performed using VG-2 (NMNH 111240-52) for $\mathrm{Si}, \mathrm{Ti}, \mathrm{Al}, \mathrm{Fe}, \mathrm{Mg}, \mathrm{Ca}$; fluorapatite (NMNH 104021) for P, Lake County labradorite (NMNH 115900) for $\mathrm{Na}$, microcline (NMNH 143966) for K. Na and K were analyzed first to reduce the volatile loss due to the electron beam. Electron beam conditions for glass were: $15 \mathrm{kV}$ accelerating voltage, $30 \mathrm{nA}$ beam current, with a $5 \mu \mathrm{m}$ diameter electron beam. Standards for plagioclase were Lake County labradorite for $\mathrm{Na}, \mathrm{Al}, \mathrm{Si}$ and $\mathrm{Ca}$, VG-2 basaltic glass for $\mathrm{Mg}, \mathrm{Fe}, \mathrm{Ti}$ and microcline for $\mathrm{K}$. Peak counting times were $5 \mathrm{~s}$ for $\mathrm{Na}, 10 \mathrm{~s}$ for $\mathrm{Si}, \mathrm{Al}, \mathrm{Ca}, \mathrm{K} ; 30 \mathrm{~s}$ for $\mathrm{Ti}$; and $60 \mathrm{~s}$ for $\mathrm{Fe}$, and $\mathrm{Mg}$. Microprobe analysis conditions for plagioclase were: $15 \mathrm{kV}$ accelerating voltage, $30 \mathrm{nA}$ beam current with a $2 \mu \mathrm{m}$ diameter electron beam. Tests on several standards were performed throughout the analytical sessions to verify that calibrations did not drift more that $1 \%$ relative.

\section{Trace Element Analysis}

Laser ablation trace element analysis were completed at the W.M. Keck Collaboratory for Plasma Spectrometry at the College of Earth, Ocean, and Atmospheric Sciences (CEOAS) at Oregon
State University using a Teledyne/Photon Machines Analyte G2 ArF Excimer laser coupled to a ThermoElemental iCAP-RQ quadrupole inductively coupled plasma mass spectrometer. Run products were analyzed for $\mathrm{Li}, \mathrm{Mg}, \mathrm{Ca}, \mathrm{Ti}, \mathrm{Sr}, \mathrm{Y}, \mathrm{Zr}, \mathrm{Nb}$, $\mathrm{Ba}, \mathrm{La}, \mathrm{Ce}, \mathrm{Nd}, \mathrm{Sm}, \mathrm{Eu}, \mathrm{Gd}, \mathrm{Dy}, \mathrm{Er}, \mathrm{Yb}, \mathrm{Hf}, \mathrm{Ta}$ and $\mathrm{Pb}$ to determine whether the systematic drift in composition observed by Drignon et al. (2018) was constrained to only major elements, or the same pattern was also observed in trace elements. These elements were selected for the variation in their diffusion rates and partition coefficients to test whether the partitioning behavior or diffusion rate elements were affected differently by the process creating the previously observed trend.

The Helex 100 sample cell configuration on this unit was designed to hold up to nine standard $1^{\prime \prime}$ microprobe rounds and is typically configured to hold six or seven "unknown" rounds with the remaining two to three positions used to hold rounds containing standard reference materials. The samples were isolated in a helium atmosphere and helium gas was used to carry the ablated particulates through Teflon tubing to the mass spectrometer. The helium gas (with transported particulates) was mixed with argon gas within the torch-box housing using a small nylon-T, just prior to introduction to the ICP torch. All ablated material was carried via ultrapure He gas flowing at $0.8 \mathrm{~L} / \mathrm{min}$ and is mixed with Ar-nebulizer gas at a flow rate between 0.95 and $1.0 \mathrm{~L} / \mathrm{min}$. Beam diameters ranged between 10 and $30 \mu \mathrm{m}$ depending on inclusion size, a laser repetition rate of $8 \mathrm{~Hz}$ was used for all analyses and laser fluence was set to $6.35 \mathrm{~J} / \mathrm{cm}^{2}$.

A typical analysis begins with a $30 \mathrm{~s}$ background reading followed by a $70 \mathrm{~s}$ acquisition period. The data are collected using time resolved analysis in peak hopping mode using a single point per peak, with $10 \mathrm{~ms}$ dwell time on each analyte. Under these conditions individual acquisitions typically lead to between 30 and 40 second-long stable, signal plateaus resulting in $\sim 0.75-1.25$ s of count time per analyte.

For some inclusions, due their morphology, the laser ablates through the inclusion into the plagioclase. To correct for this, all of the data were back calculated using electron microprobe $\mathrm{MgO}$ abundances to minimize the effect of plagioclase contamination. This was done by assuming the Mg measured via LA-ICP-MS should have a 1:1 ratio with $\mathrm{Mg}$ measured by EMPA. The MI composition was calculated by projecting to the known $\mathrm{MgO}$ abundances of the $\mathrm{MI}$ and the host as per Nielsen et al. (2017). Sr and Ba concentrations for the MI were estimated using the plagioclase/melt partition coefficients calculated using the constraints of Nielsen et al. (2017) based on the measured An content of the host and $1,230^{\circ} \mathrm{C}$. Inclusions that required more than $30 \%$ correction were discarded (10\% of analyses performed).

\section{RESULTS}

\section{Major Element Variation With Heating Time}

Changes in melt inclusion composition as a function of time were measured for both the Blanco Fracture Zone and Juan de Fuca Ridge samples for five time intervals including $30 \mathrm{~min}, 4 \mathrm{~h}, 1$ day, 4 days, and 8 days (Figures 1,2 ). Mg and Si in MI increases with 

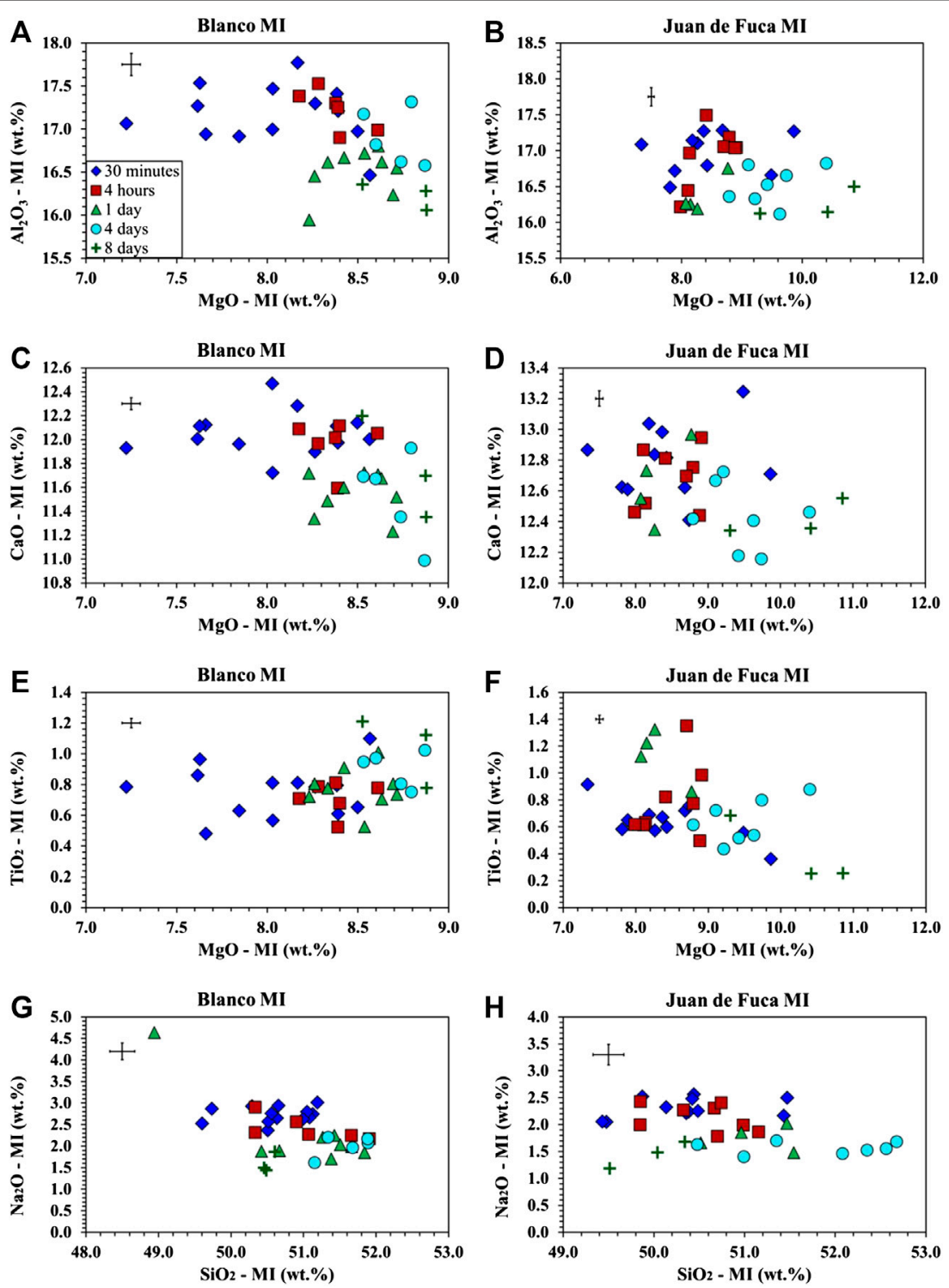

FIGURE 1 | Major element analysis of Mls from the Juan de Fuca Ridge (D23-2) and the Blanco Fracture Zone (A91-1R1) samples following homogenization at 1 bar. Symbols for run time is consistent across all major element plots with 30 min as blue diamonds, $4 \mathrm{~h}$ as red squares, 1 day as green triangles, 4 days as aqua circles, and 8 days as dark green crosses. Error bars are located in the upper left hand corner of each plot. (A) Al $\mathrm{O}_{3}$ vs. MgO for A91-1R1 (Blanco Fracture Zone) shows a decrease in $\mathrm{Al}_{2} \mathrm{O}_{3}$ and an increase in $\mathrm{MgO}$ with time. (B) $\mathrm{Al}_{2} \mathrm{O}_{3}$ vs. $\mathrm{MgO}$ for D23-2 (Juan de Fuca) shows a decrease in $\mathrm{Al}_{2} \mathrm{O}_{3}$ and an increase in $\mathbf{M g O}$ with time. (C) $\mathrm{CaO}$ vs. MgO for A91-1R1 (Blanco Fracture Zone) shows a decrease in $\mathrm{CaO}$ and an increase in MgO. (D) CaO vs. MgO for D23-2 (Juan de Fuca) shows a decrease in $\mathrm{CaO}$ and an increase in $\mathrm{MgO}$. (E) $\mathrm{TiO}_{2}$ vs. MgO for A91-1R1 (Blanco Fracture Zone) correlating TiO $\mathrm{T}_{2}$ and MgO. (F) TiO 2 vs. MgO for the D23-2 (Juan de Fuca) correlating $\mathrm{TiO}_{2}$ and an increase in MgO. (G) $\mathrm{Na}_{2} \mathrm{O}$ vs. $\mathrm{SiO}_{2}$ for A91-1R1 (Blanco Fracture Zone) shows a decrease in $\mathrm{Na}_{2} \mathrm{O}$ and an increase in $\mathrm{SiO} \mathrm{O}_{2}$ outside of 8 days experiments. (H) $\mathrm{Na}_{2} \mathrm{O}$ vs. $\mathrm{SiO}_{2}$ for D23-2 (Juan de Fuca) shows a decrease in $\mathrm{Na}_{2} \mathrm{O}$ and an increase in $\mathrm{SiO}_{2}$ outside of 8 days experiments.

time while $\mathrm{Ca}, \mathrm{Al}$, and $\mathrm{Na}$ decrease. The exception is the 8-day runs which do not follow the trend of increasing Si. Ti shows compositional change with time, but the trends are different for each sample. Ti increases with time for MIs in plagioclase from the Blanco sample, but decreases with time for MIs in plagioclase from the sample of the West Valley of the Juan de Fuca. Regardless of this, longer periods of homogenization are tied to compositional drift. Similar trends are observed for inclusions in both the Blanco Fracture Zone and Juan de Fuca samples.

\section{Major Element Profiles}

Traverses of EMPA analyses from the plagioclase host into the MI (Figures 3A-C, 4A-B) show that the area around MIs are lower in $\mathrm{Mg}$ compared to the host (away from $\mathrm{MI} /$ far-field host) in the longest (4- and 8-day) experiments. It is important to note that the zone of excitation of the electron beam is $2 \mu \mathrm{m}$ and thus the values reported are minima. Similar patterns are not seen in the shorter ( $30 \mathrm{~min}, 4 \mathrm{~h}$, and 1 day) experiments. As noted in Electron Microprobe Analysis, two traverses were done on 

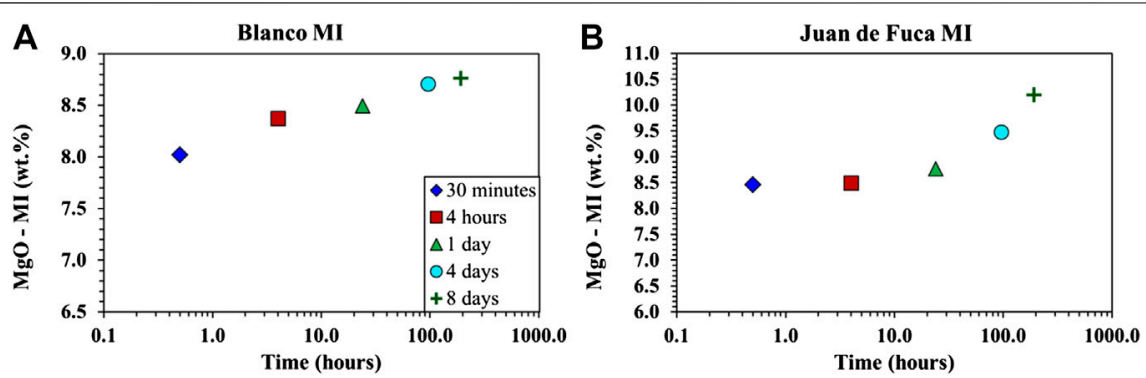

FIGURE 2 | Averaged point analysis per time group for low pressure samples. Symbols include 30 min average as a blue diamond, 4 hours average as a red square, 1 day average as a green triangle, 4 days average as an aqua circle, and 8-days average as a dark green cross. (A) Time vs. MgO for the Blanco fracture zone (A91-1R1) averaged time groups. (B) Time vs. MgO for the Juan de Fuca Ridge (D23-2) averaged time groups.
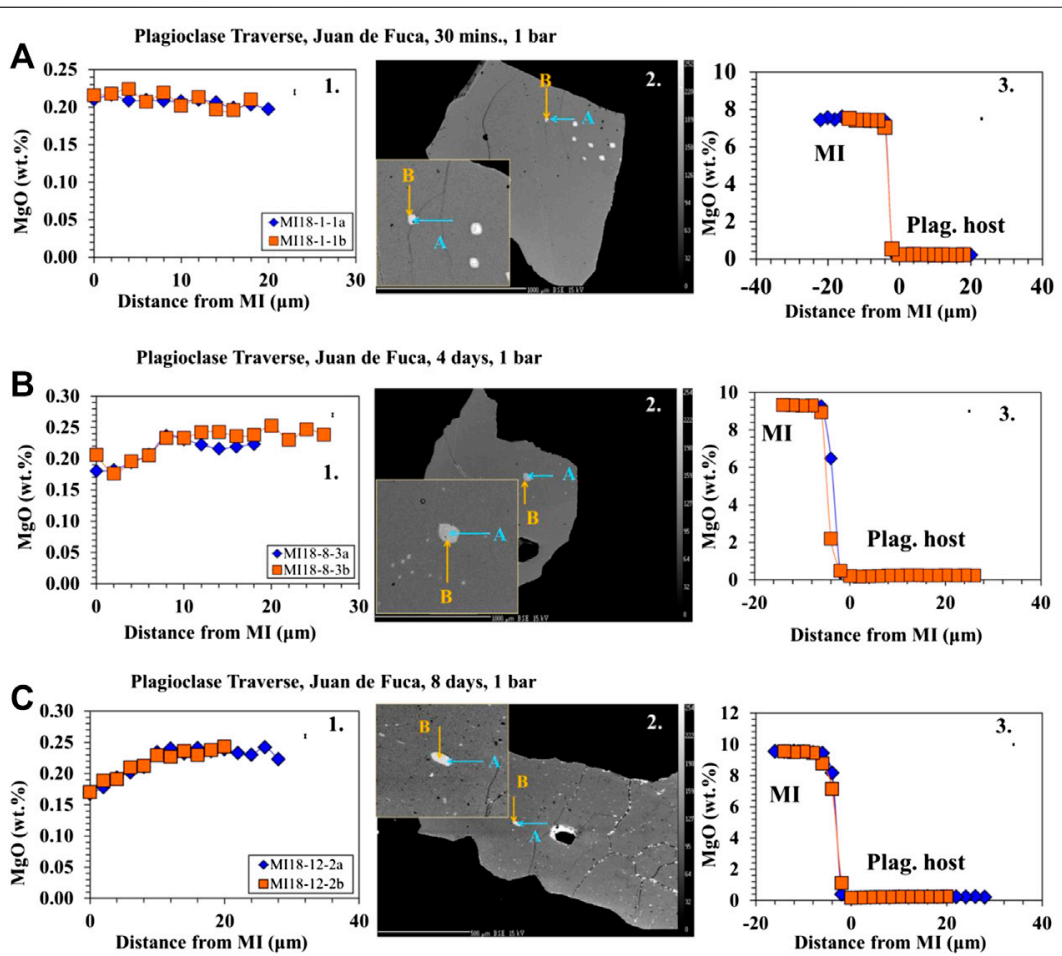

FIGURE 3 | Major element profiles between the host plagioclase and the Mls for low pressure experiments. 1) The profile from the plagioclase host (right) into the MI (left) marked by an increase in MgO. Error bars are located in the upper right corner. 2) BSE images showing the direction and location of traverses. 3) Profile within the plagioclase host as it approaches the boundary of the MI (marked by 0 distance from MI). (A) Profiles and BSE on a 30 minute-low pressure Juan de Fuca sample-D23-2. Results show no change in MgO as the traverse approaches the Ml boundary. (B) Profiles and BSE on 4 days Juan de Fuca-D23-2 low pressure sample. Results show a decrease in MgO as the traverse approaches the Ml boundary. (C) Profiles and BSE on 8 days-low pressure Juan de Fuca-D23-2 sample. Results show a

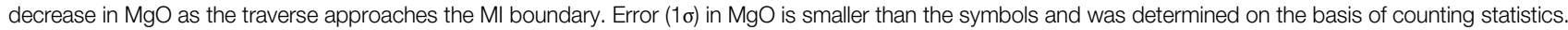

each MI from different directions to assess the possible influence of crystallographic orientation. The two different traverses are set at $90^{\circ}$ to each other. We did not determine the crystallographic orientation prior to analysis, but as there were minimal differences between the two traverses on all analysis, crystallographic orientation was determined to be inconsequential.

The morphology of MI in these samples is highly variable. Most small inclusions are spherical, with increasing numbers of disc-shaped inclusions among the larger MI population (see BSE images of MIs-Figure 3). In addition, MI occur as isolated bodies or in bands associated with zoning patterns. Two phase melt inclusions are restricted to spinel + melt and vapor + melt olivine is never found as part of a binary phase MI (as reported by Nielsen et al., 2020). However, small olivine daughter crystals $(<5$ microns) are common in MIs that have not been heated (naturally quenched - see images in Drignon et al., 2019). This is consistent with previous observations of MIs in 

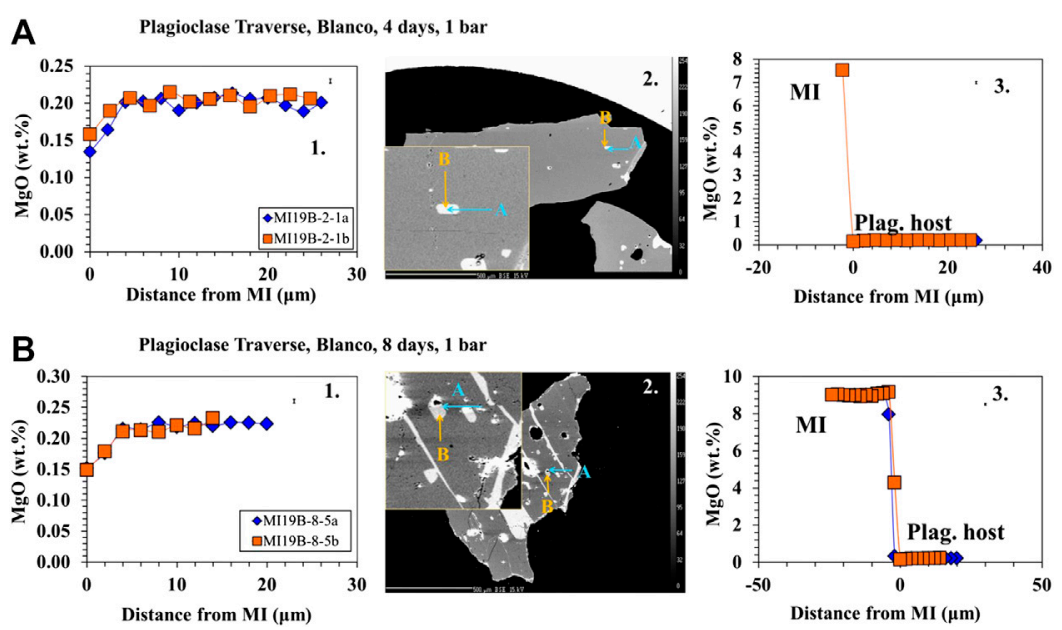

FIGURE 4 | Major element profiles between the host plagioclase and the Ml for low pressure experiments. 1) The profile from the plagioclase host (right) into the Ml (left) marked by an increase in MgO. Error bars are located in the upper right corner. 2) BSE images showing the direction and location of traverses. 3) Profile within the plagioclase host as it approaches the boundary of the MI (marked by 0 distance from MI). (A) Profiles and BSE on 4-day Blanco-A91-1R1 low pressure sample. Results show a decrease in $\mathrm{MgO}$ as the traverse approaches the Ml boundary. (B) Profiles and BSE on 8-day low pressure Blanco-A91-1R1 sample. Results show a decrease in $\mathrm{MgO}$ as the traverse approaches the Ml boundary. The bands of melt (light grey) across the crystal (medium grey) represent melt present along fractures, presumably cleavage planes. A number of other breached Mls are present in the same image.

plagioclase megacrysts (see compilation of plagioclase-hosted MI images in Nielsen et al., 2017). The increased tendency for irregular (non-spherical) morphologies in plagioclase-hosted inclusions is consistent with the observations of the MI formation experiments of Kohut and Nielsen (2004). The shape of MIs is a complex function of degree of undercooling and crystal growth rate.

The results from the traverses between the plagioclase host and MI for Juan de Fuca and Blanco samples (Figures 3A-C, 4A-B) document that in the 4- and 8-days runs, $\mathrm{MgO}$ in the plagioclase drops by $\sim 25 \%$ in the $5-10$ microns closest to the inclusion. This drop in $\mathrm{MgO}$ near the inclusion is not observed for the shorter run experiments. The width of the zone of lower $\mathrm{MgO}$ in the 4days experiments varies for different MIs. We did not assess the possible influence of the third dimension. The resultant profiles depend on the angle between the polished surface and the MI/ plagioclase interface. If the MI/host interface intersects the surface orthogonally, one would expect a narrower profile to be sampled compared to the case where the MI/host interface intersected the surface at a high angle. There is minimal difference between the two traverses in all cases regardless of run time, thus the change in $\mathrm{MgO}$ is not controlled by crystallographic orientation. Experiments with a large change in melt inclusion $\mathrm{MgO}$ content show a significant $\mathrm{Mg}$ depletion halo at the MI/host interface. This profile is observed primarily in the 4- and 8- days experiments is consistent with a model where $\mathrm{Mg}$ diffuses "uphill" from the plagioclase host into the MI (Figures 3B,C, 4A-B). While the compositional drift also occurs in 4-hour and 1-day runs as seen in the MI point analysis, the profile from the plagioclase into the MI is not large enough to be observed in the traverses. As diffusion does not have an effect on $30 \mathrm{~min}$ run products, no trends are found to be visible (Figure 3A).

\section{Trace Element Profiles}

The results of the major element analysis document a drift in composition with time primarily observed in $\mathrm{MgO}(\sim 1-1.5 \mathrm{wt} \%$ Figures 1, 2). This leads to the question of whether the trace elements contents are affected by heating time and whether or not the heterogeneity in MI and megacrysts compositions reported in earlier investigations can be attributed to the homogenization process (Nielsen et al., 1995; Sours-Page et al., 1999; Cottrell et al., 2002). As mentioned earlier, several different trace elements were selected on the basis of differing partitioning behavior between plagioclase and basaltic glass (MI) ( $\mathrm{Zr}, \mathrm{Nb}$-lowest; $\mathrm{Ti}, \mathrm{Mg}$, Ce-low; Ba-medium; Sr-high) (Bindeman et al., 1998) and diffusion rates ( $\mathrm{Zr}, \mathrm{Nb}$-slowest; $\mathrm{Ce}, \mathrm{Ti}$-slow; $\mathrm{Ba}$-medium; $\mathrm{Sr}$, Mg-fast) (Cherniak and Watson, 2020; Nielsen et al., 2020).

We expected to observe one of two possible outcomes. The first is a mirrored phenomenon of what is observed in the major element results; that there is compositional drift with increasing homogenization time. The second is a cone of equilibration where trace element variability decreases with increasing homogenization time. The only trace element noted to show any correlation with run time is Ti (Figures 5A,B). Ti exhibits decreasing abundance with time in the Juan de Fuca Ridge sample, while exhibiting a slight increase in $\mathrm{Ti}$ for Blanco Fracture Zone sample (Figures 5A,B). However, the range of $\mathrm{Ti}$ for any specific run time remains the same (e.g. not convergence). $\mathrm{Sr}, \mathrm{Nb}, \mathrm{Ba}, \mathrm{Ce}$, and $\mathrm{Zr}$ (Figures 5C-F, 6A-F) exhibit no systematic change as a function of run time, and more important, exhibit no convergence as a function of run time. Such a convergence is what was predicted by Nielsen et al. (1995) and documented for compatible elements in plagioclase hosted MI by Cottrell et al. (2002). The wide range of highly incompatible, slowly diffusing trace elements is common in plagioclase-hosted inclusions (Nielsen et al., 1995; Nielsen et al., 2017; Nielsen et al., 

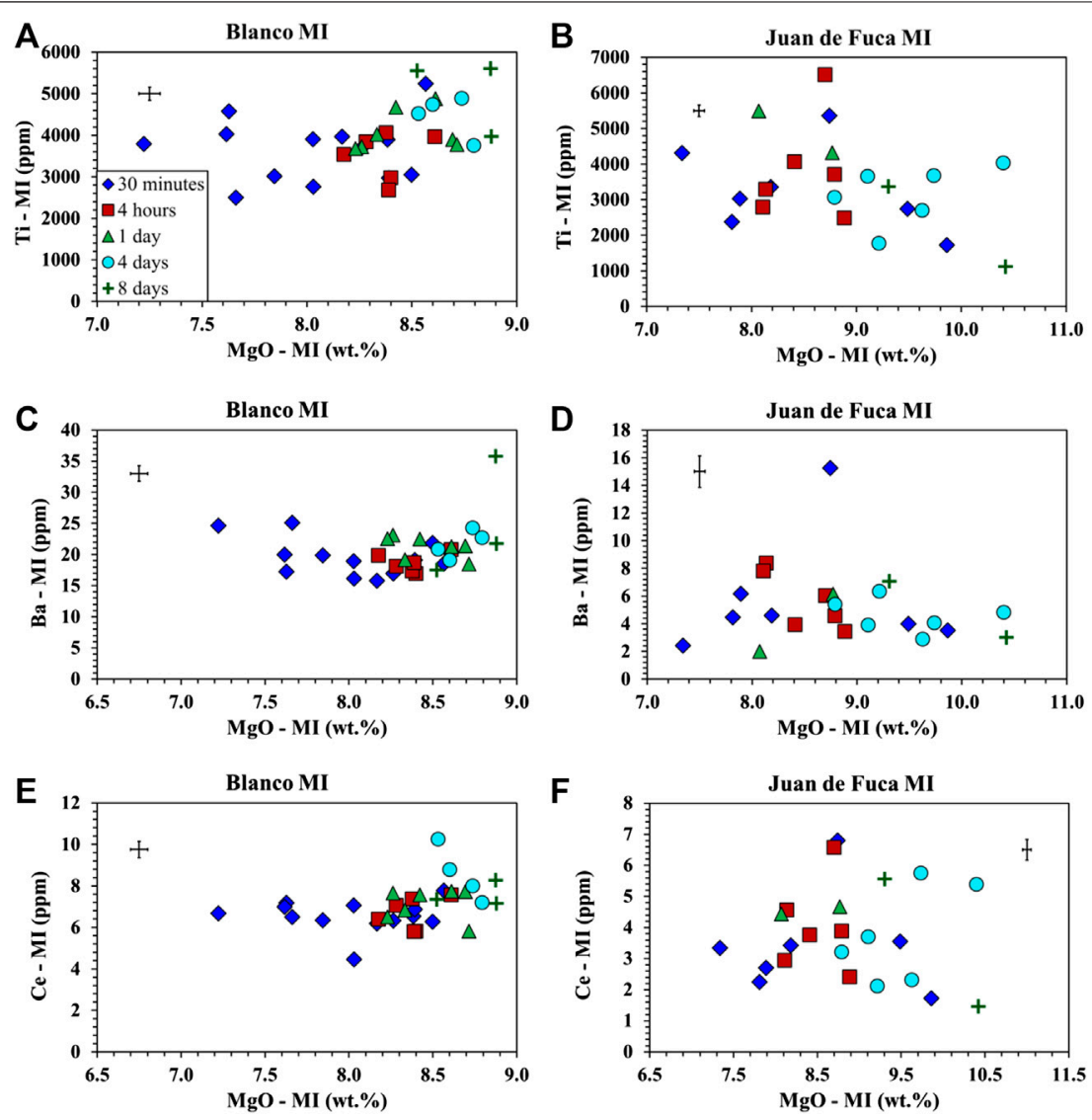

FIGURE 5 | Trace element analysis of Ml obtained by LA-ICP-MS following homogenization at 1 bar for samples from the Juan de Fuca Ridge (D23-2) and the Blanco Fracture Zone (A91-1R1). Symbols as in Figure 1. Error bars are located in the upper left or right corner of each plot. (A) Ti vs. MgO for A91-1R1 (Blanco Fracture Zone) shows an increase in Ti and an increase in MgO with time. (B) Ti vs. MgO for D23-2 (Juan de Fuca) shows a decrease in Ti and an increase in MgO with time. (C) Ba vs. MgO for A91-1R1 (Blanco Fracture Zone) shows no trend in Ba and an increase in MgO. (D) Ba vs. MgO for D23-2 (Juan de Fuca) shows no trend in Ba and an increase in MgO. (E) Ce vs. MgO for A91-1R1 (Blanco Fracture Zone) shows a slight increase in Ce and an increase in MgO. (F) Ce vs. MgO for D23-2 (Juan de Fuca) shows no trend in $\mathrm{Ce}$ and an increase in $\mathrm{MgO}$.

2020). The absence of either a convergent or divergent pattern supports the contention that the concentration of such elements (e.g. $\mathrm{Zr}, \mathrm{Nb}$ ) in $\mathrm{MI}$ represents a primary signal (Nielsen et al., 2017, Nielsen et al., 2020).

\section{Role of Pressure on Homogenization}

Two sets of high pressure experiments were completed at $7.5 \mathrm{kbar}$ with run times of 2 and 4 days for both the Juan de Fuca Ridge and Blanco Fracture Zone samples. Analyses of Cs and I were done on the charges to evaluate whether or not the packing medium of cesium iodide was suitable for plagioclase (i.e. diffusion did not occur between the packing material and crystal) and to validate the experimental parameters (temperature, time, etc). The results showed that Cs and I were below the detection limits for the EMP, and therefore there was no evidence of diffusive exchange with the packing materials. One 4-day high pressure experiment using crystals from the Blanco fracture zone yielded melt inclusions characterized by a homogeneous glass center with $\sim 5-10 \mu \mathrm{m}$ quench crystallization within the MI along the MI/host interface. This quench growth occurred in spite of the fact that the assembly cooled to less than $400^{\circ} \mathrm{C}$ within $5 \mathrm{~s}$. The quench crystals were too small to analyze individually but appear dark in the BSE images and were therefore assumed to be plagioclase. Growth of these crystals caused the melt at the MI/host to become enriched in $\mathrm{Mg}$ and Fe compared to the MI core (Figure 7). The 2- and 4-day high pressure experiments did not exhibit the trend of higher $\mathrm{Mg}$ in the MI, nor the lower Mg in the host as one approached the MI interface that are found in the 1 bar, 4 - and 8-day experiments (Figure 7).

\section{Size Dependency}

Based on the observation that the $\mathrm{MI} /$ host traverses exhibit trends of different magnitudes, we examined a number of parameters that could be linked to the size of the depletion halo around the $\mathrm{MI}$, as well as the average increase in melt inclusion $\mathrm{Mg}$ content as a function of experimental run time. If the migration of $\mathrm{Mg}$ into the MI was dependent on MI surface area, one might expect a 

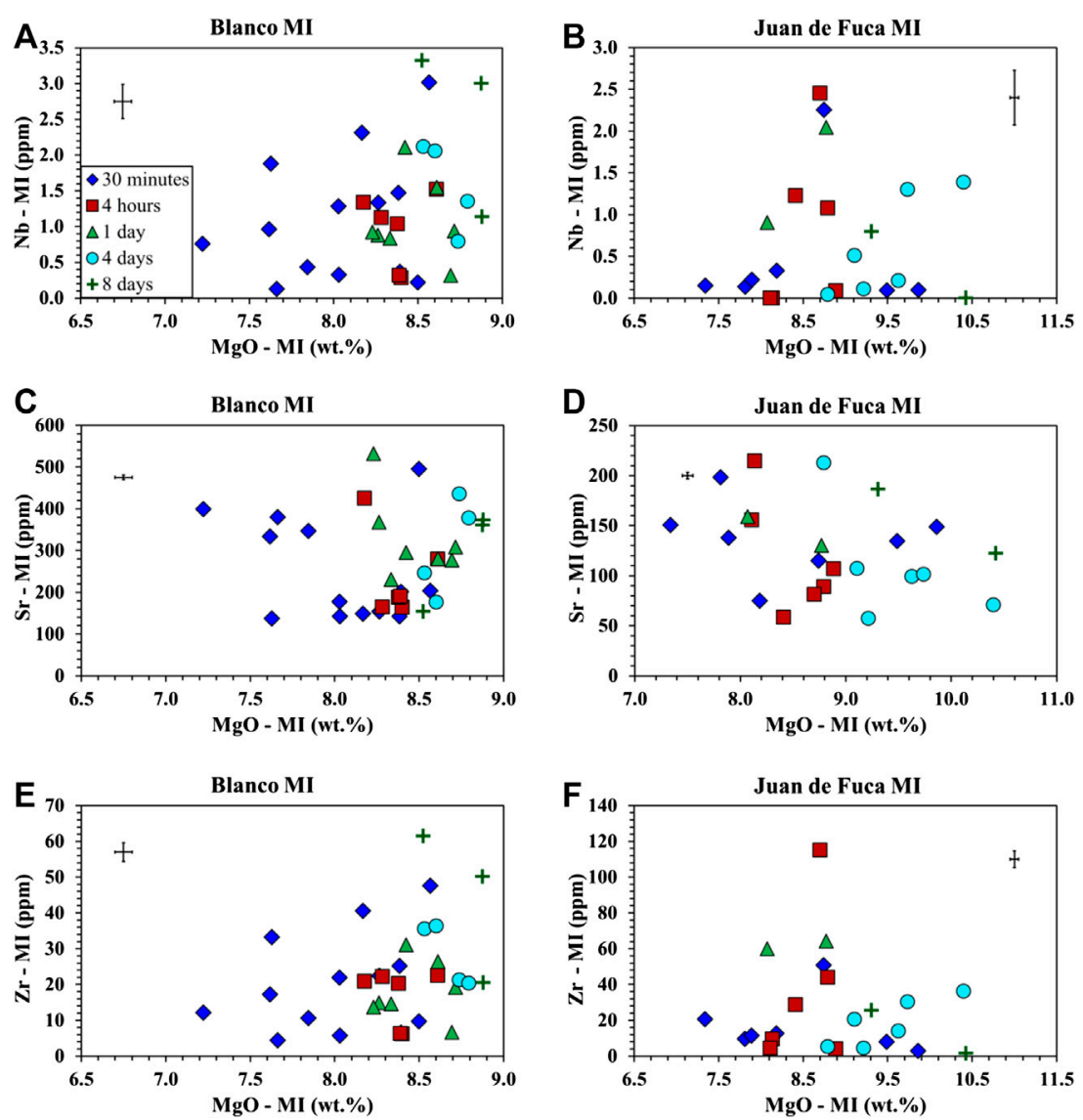

FIGURE 6 | Trace element analysis of Ml following homogenization at 1 bar for samples from the Juan de Fuca Ridge (D23-2) and the Blanco Fracture Zone (A911R1). Symbols as in Figure 1. Error bars are located in the upper left or right corner of each plot. (A) Nb vs. MgO for A91-1R1 (Blanco Fracture Zone) shows no trend in $\mathrm{Nb}$ and an increase in MgO. (B) Nb vs. MgO for D23-2 (Juan de Fuca) shows no trend in Nb and an increase in MgO. (C) Sr vs. MgO for A91-1R1 (Blanco Fracture Zone) shows no trend in Sr and MgO. (D) Sr vs. MgO for D23-2 (Juan de Fuca) shows no trend in Sr and an increase in MgO. (E) Zr vs. MgO for A91-1R1 (Blanco Fracture Zone) shows no trend in $\mathrm{Zr}$ and an increase in $\mathrm{MgO}$ with time. (F) $\mathrm{Zr}$ vs. MgO for D23-2 (Juan de Fuca) shows no trend in $\mathrm{Zr}$ and an increase in MgO with time.

negative correlation of $\mathrm{Mg}$ change with inclusion radius because the surface area to volume ratio decreases with increasing MI radius, and thus each unit volume of liquid would have less host with which to interact. In contrast, if the migration of $\mathrm{Mg}$ was dependent on the extent of deformation, increase in inclusion volume and resultant pressure drop, then one might expect a positive correlation. This is because surface area is square function of radius while volume is a cube function (Tait, 1992; Zhang, 1998). For the purpose of this comparison, we calculated $\Delta \mathrm{Mg}$ based on the difference between the average $\mathrm{Mg}$ for the 30 min run time experiments, with the MI Mg for each individual $\mathrm{MI}$ from the $4 \mathrm{~h}$ run time experiments. This $\Delta \mathrm{Mg}$ value used the average MI composition from the 30-min runs as the base line. Note that volume increased as a cube function of radius, while surface area was a squared function. Our results (Figure 8) exhibit a positive correlation of the MI radius and the change in $\mathrm{Mg}$ among individual 4-days inclusions and the averaged 30min $\mathrm{Mg}$ value, consistent with greater extent of deformation for larger inclusions. Again, this is consistent with the predictions of Tait (1992).

\section{DISCUSSION}

There are several factors that must be taken into consideration when homogenizing melt inclusions if we are to produce accurate constraints on the magmas from which the crystals form. Temperature, time, pressure, host composition, melt inclusion size, etc. all play an important role. Since the goal of homogenization is to re-create the composition of entrapment, it is important that the process does not cause progressive changes in the MI composition.

Drift in MI MgO content is correlated with experimental run time. The extent of change in MI MgO content and the magnitude of the depletion zone at the $\mathrm{MI} /$ host interface are dependent on time and therefore most evident in long run time experiments (4 and 8 days). Most major and trace elements exhibit similar or no correlation with time in each of the two samples. The sole exception is $\mathrm{Ti}$, which increases in Blanco Fracture Zone samples (A91-1R1) but decreases in the Juan de Fuca Ridge as a function of run time (D23-2) (Figures 1E-F, 5A-B). This suggests that the partitioning behavior may be different for the different MIs 

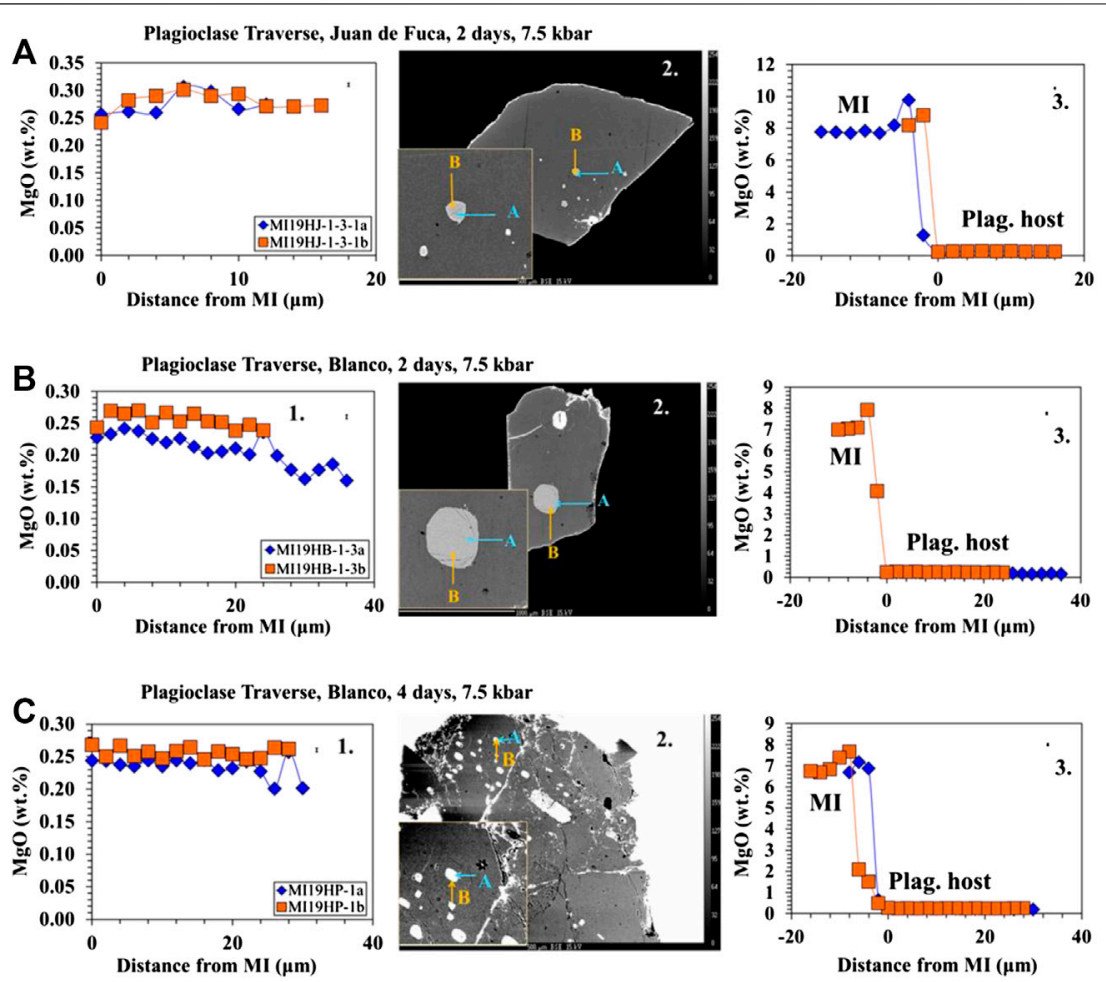

FIGURE 7 | Major element profiles between the host plagioclase and the Ml for high pressure experiments. 1) The profile from the plagioclase host (right) into the MI (left) marked by an increase in $\mathrm{MgO}$. Spike in $\mathrm{MgO}$ within the $\mathrm{Ml}$ is a result of quench crystallization. Error bars are located in the upper right corner. 2) BSE images showing the direction and location of traverses. 3) Profile within the plagioclase host as it approaches the boundary of the MI (marked by 0 distance from MI). (A) Profiles and BSE on 2-day high pressure experiments for Blanco and Juan de Fuca samples. Results show no change in MgO as the traverse approaches the Ml boundary, but an increase in MgO at the inner boundary of the MI. (B) Profiles and BSE on 4-day high pressure experiments for Blanco sample. Results show a no change in MgO as the traverse approaches the $\mathrm{Ml}$ boundary, but an increase in $\mathrm{MgO}$ at the inner boundary of the $\mathrm{Ml}$.

and host compositions, or even small differences in temperature. It has been documented that plagioclase-melt partition coefficients for $\mathrm{Ba}, \mathrm{Sr}, \mathrm{Ti}, \mathrm{Zr}$, and the REEs are negatively correlated with both temperature and An content (D increases as temperature and anorthite content of plagioclase decreases) (Blundy and Wood, 1991; Dohman and Blundy, 2014; Nielsen et al., 2017). As noted in Melt Inclusions as Proxies, the precision and amount of plagioclase/melt partitioning data available at elevated pressure is insufficient to model partitioning in plagioclase quantitatively. If the experimental temperature and pressure were representative of the conditions at the time of entrapment, there should be no changes in MI or host composition as a function of experimental run time. As described in Low Pressure Homogenization Experiments, all crystals in this study were heated to $1,230^{\circ} \mathrm{C}$ at low pressure and $1,275^{\circ} \mathrm{C}$ at high pressure, which was determined using phase equilibria calculations, experimental results and the disappearance of the daughter crystals (Blundy and Wood, 1991; Lange et al., 2013a; Lange et al., 2013b; Drignon et al., 2019). If either of those constraints on entrapment temperature were off by as much at $10-15^{\circ} \mathrm{C}$, one might expect a change in partitioning behavior (Dohman and Blundy, 2014; Nielsen et al., 2017). This may explain the different results for Ti in the two different samples. In particular, both samples, while differing in anorthite content, were homogenized at the same temperature-again based on both phase equilibria and independent heating stage work. It is believed, based on the behavior of Ti, that the Juan de Fuca samples may have been underheated. In addition, repeated heating and cooling will result in crystal relaxation. When homogenization temperatures are determined by heating stage, it is not uncommon for the temperature at which the bubble disappears to increase as the MI is reheated (Danyushevsky et al., 2000; Drignon et al., 2019). This will lead to erroneously high estimates for entrapment temperature, and potentially increase the rate of compositional drift.

Over or underheating may change the behavior of certain major and trace elements thus effecting the overall composition. This could be the potential cause of the opposite trends for Ti in the Juan de Fuca and Blanco samples present in the EMP and LA-ICP-MS data. These two samples are compositionally distinct but were both homogenized at the same temperature $\left(1,230^{\circ} \mathrm{C}\right)$. Given the results, it is reasonable to conclude that each sample should be homogenized at different temperatures depending on composition. While phase equilibria and heating stage gave the same temperature for both samples, it is only accurate to within $10-15^{\circ} \mathrm{C}$. Thus, it is possible that the Juan de Fuca samples were underheated. It is important to note here that plagioclase megacrysts are typically not in equilibrium with the magma in which they are transported to the surface (Lange et al., 2013a; Lange et al., 2013b). Therefore, during transport, they may reside for 


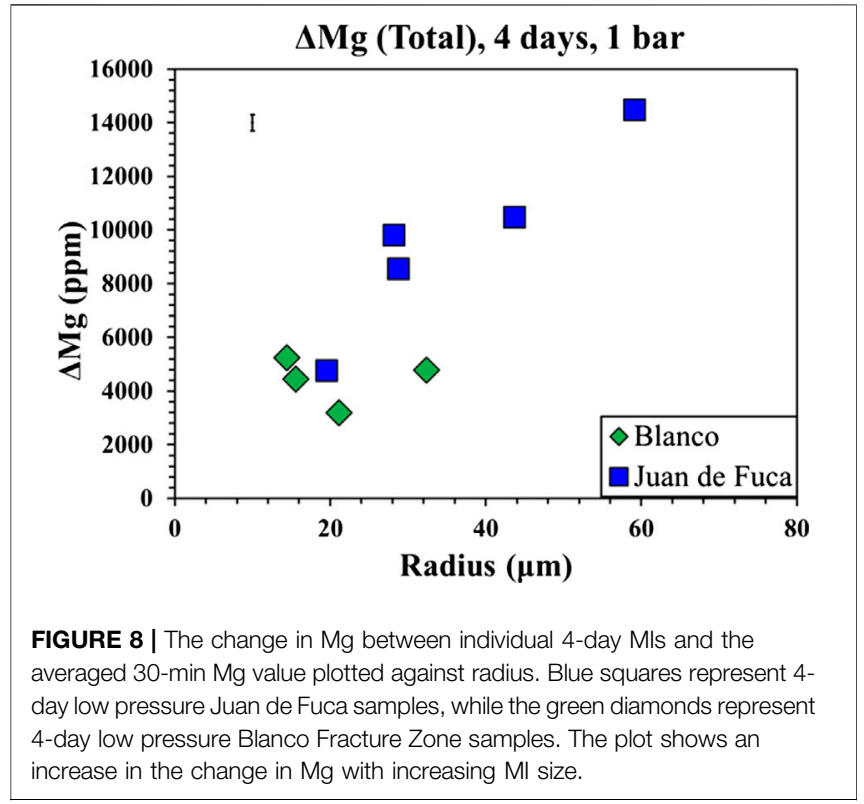

hours, days, weeks or more in magmas at much higher or lower temperature than that representative of their formation. Thus, understanding the sensitivity of MI composition to temperature is not just relevant to the effects of homogenization in the laboratory but also has implications for the conditions that megacrysts that are exposed to during transport.

The homogenization experiments were run at two different pressures to constrain the causes of compositional drift, which has previously been attributed to crystal relaxation (Schiavi et al., 2016; Drignon et al., 2019). Low pressure experiments (1 bar) are representative of the surface pressure while the high pressure experiments $(7.5 \mathrm{kbars})$ represent the pressure of the upper mantle/lower crust. We selected the $7.5 \mathrm{kbars}$ for the high pressure experiments because that value falls within the range of entrapment pressures calculated by Drignon et al. (2018) based on $\mathrm{CO}_{2}$ contents in MI. To evaluate whether or not crystal relaxation or disequilibrium is causing compositional drift, the 1 bar and 7.5 kbars results were compared. The high pressure runs did not exhibit drift or the $\mathrm{MgO}$ profile displayed in the long (4- and 8-day) low pressure runs. If the MI were out of equilibrium at the time of entrapment, both low- and high pressure experiments would show the same profile caused by equilibration between the plagioclase host and MI. As the traverse profiles of the high pressure experiments are similar to those displayed in the $30 \mathrm{~min}$ low pressure experiments, our results are consistent with the interpretation that crystal relaxation is the main cause for compositional drift. During homogenization at low pressure, the crystal deforms in response to the internal pressure of the MI (Tait, 1992) and the lower (1 bar) confining pressure. As per the conclusions of Drignon et al. (2019), this may cause changes in the partitioning behavior of certain elements allowing for compositional drift to occur. Further, large inclusions have greater internal pressure drop as the crystal deforms (Tait, 1992; Zhang, 1998), potentially resulting in greater pressure related compositional drift.
TABLE 1 | Experimental conditions for melt inclusion homogenization experiments for Blanco fracture zone and Juan de Fuca ridge samples.

\begin{tabular}{|c|c|c|c|c|}
\hline & \# of Melt & Pressure & Temperature & Duration \\
\hline Composition & Inclusions & $(\mathrm{P})$ & $(T)$ & $(t)$ \\
\hline \multicolumn{5}{|c|}{ Blanco (A91-1R1) } \\
\hline Ml19B-1 & 6 & 1 bar & $1,230^{\circ} \mathrm{C}$ & $30 \mathrm{~min}$ \\
\hline Ml19B-2 & 5 & 1 bar & $1,230^{\circ} \mathrm{C}$ & 4 days \\
\hline Ml19B-3 & 4 & 1 bar & $1,230^{\circ} \mathrm{C}$ & 1 day \\
\hline Ml19B-4 & 5 & 1 bar & $1,230^{\circ} \mathrm{C}$ & $4 \mathrm{~h}$ \\
\hline Ml19B-5 & 1 & 1 bar & $1,230^{\circ} \mathrm{C}$ & $4 \mathrm{~h}$ \\
\hline Ml19B-6 & 5 & 1 bar & $1,230^{\circ} \mathrm{C}$ & 1 day \\
\hline Ml19B-7 & 7 & 1 bar & $1,230^{\circ} \mathrm{C}$ & $30 \mathrm{~min}$ \\
\hline Ml19B-8 & 3 & 1 bar & $1,230^{\circ} \mathrm{C}$ & 8 days \\
\hline Ml19HB-1 & 3 & 7.5 kbars & $1,275^{\circ} \mathrm{C}$ & 2 days \\
\hline Ml19HP & 2 & 7.5 kbars & $1,275^{\circ} \mathrm{C}$ & 4 days \\
\hline \multicolumn{5}{|c|}{ Juan De Fuca (D23-2) } \\
\hline Ml18-1 & 1 & 1 bar & $1,230^{\circ} \mathrm{C}$ & $30 \mathrm{~min}$ \\
\hline Ml18-2 & 2 & 1 bar & $1,230^{\circ} \mathrm{C}$ & $4 \mathrm{~h}$ \\
\hline Ml18-3 & 1 & 1 bar & $1,230^{\circ} \mathrm{C}$ & 1 day \\
\hline Ml18-4 & 2 & 1 bar & $1,230^{\circ} \mathrm{C}$ & 4 days \\
\hline Ml18-5 & 0 & 1 bar & $1,230^{\circ} \mathrm{C}$ & $30 \mathrm{~min}$ \\
\hline Ml18-6 & 0 & 1 bar & $1,230^{\circ} \mathrm{C}$ & $4 \mathrm{~h}$ \\
\hline Ml18-7 & 3 & 1 bar & $1,230^{\circ} \mathrm{C}$ & 1 day \\
\hline Ml18-8 & 2 & 1 bar & $1,230^{\circ} \mathrm{C}$ & 4 days \\
\hline Ml18-9 & 2 & 1 bar & $1,230^{\circ} \mathrm{C}$ & $30 \mathrm{~min}$ \\
\hline Ml18-10 & 6 & 1 bar & $1,230^{\circ} \mathrm{C}$ & $4 \mathrm{~h}$ \\
\hline Ml18-11 & 3 & 1 bar & $1,230^{\circ} \mathrm{C}$ & 4 days \\
\hline Ml18-12 & 3 & 1 bar & $1,230^{\circ} \mathrm{C}$ & 8 days \\
\hline Ml18-13 & 8 & 1 bar & $1,230^{\circ} \mathrm{C}$ & $30 \mathrm{~min}$ \\
\hline Ml19HJ-1 & 5 & 7.5 kbars & $1,275^{\circ} \mathrm{C}$ & 2 days \\
\hline
\end{tabular}

Low (1 bar) pressure experiments were conducted in platinum (Pt) foil, and high pressure (7.5 kbars) experiments were conducted in Pt capsules. Reported oxygen fugacity refers to the $\mathrm{fO}_{2}$ experienced by plagioclase host at the time of entrapment but not to furnace atmosphere. Based on the Eu anomaly measured for the melt inclusions and the plagioclase host for similar experiments of ours on the same composition by Dygert et al., 2020, the $\mathrm{fO}_{2}$ was determined as within a half a log unit below FMQ.

During homogenization at high pressure, the experimental pressure is closer to the pressure of entrapment, hence the absence of compositional drift. These findings imply that homogenization should be done at the pressure of MI entrapment. Our high pressure results were not quenched quickly enough for the glass to be homogenous and without the formation of post-entrapment crystals along the side-wall of the MI. In order to utilize these findings, a faster quenching method is necessary. Some of the other issues arise from high pressure experiments include fracturing of crystals regardless of packing material of cesium iodide. Until these issues are addressed, homogenization at short run times $(30 \mathrm{~min})$ at $1 \mathrm{bar}$ is an accommodating method which allows for removal of post-entrapment crystallization, rapid quenching, and lack of compositional drift as the crystal has not had time to relax.

While we ascribe crystal relaxation in the form of plastic deformation as the primary mechanism driving compositional drift, it is possible that local disequilibrium is still a factor. Although the major elements show consistent behavior, specific trace elements $(\mathrm{Nb}, \mathrm{Sr}, \mathrm{Zr})$ are variable and show no drift or convergence with homogenization time. Adams et al. (2011), Lange et al. (2013a), Lange et al. (2013b), and Nielsen et al. (2020) attributed the observed wide range of trace element compositions in plagioclase megacrysts and their inclusions to 
the trapping of melts from different mantle source regions while reaction with the wall rock resulted in buffering the major element compositions. $\mathrm{Nb}, \mathrm{Sr}, \mathrm{Zr}$ show this variability, while other trace elements show weak correlations. This may be a factor of element compatibility as elements will re-equilibrate quickly when compatible in plagioclase (Cottrell et al., 2002) in addition to the diffusion rate of the element. However, comparison of MI compositions with the composition of the hosts near the MI (in the form of $\mathrm{MI} /$ host partition coefficients) yields values close to experimental values (Nielsen et al., 2017).

Another factor to consider when analyzing homogenized MIs is the size of those inclusions. Compositional drift is larger in larger inclusions (Figure 8). In a study of the selective preservation of melt inclusions, Tait (1992) concluded that smaller inclusions will preferentially withstand rupture and that, for most naturally occurring inclusions sizes, the host will function as an infinite reservoir. Our results may be interpreted to indicate that the internal pressure within the inclusion, a function of volume (Tait, 1992; Zhang, 1998), is more important than surface area of the inclusion in controlling the observed compositional drift. In addition, the fact that larger inclusions did not rupture (as determined by their $S$ contents-Nielsen et al., 1998), but rather exhibited greater compositional change, may be interpreted as an indication that the deformation of the plagioclase was plastic (not brittle) and that smaller inclusions will exhibit less deformation than larger inclusions.

An important implication of these results pertains to how analysts select inclusions for analysis. Most analysts prefer large MIs as they are easier to identify and to obtain uncontaminated analyses of glass. To minimize the effect of compositional drift, one would choose to analyze small inclusions. However, this may be difficult for certain analytical methods. Current limits of LAICP-MS analysis are a beam size of $10-30 \mu \mathrm{m}$. This is similar to the lower end of the range of most melt inclusions particularly in feldspar (Figure 8). If homogenization is restricted to $30 \mathrm{~min}$ in plagioclase-hosted inclusions, MI size should not be an issue as crystal relaxation will not yet modify the composition. This holds true for our experiments on plagioclase-hosted MIs but may not be the case for olivine-hosted ones (Schiavi et al., 2016) due to the comparatively rapid rate of deformation for olivine. The observed correlation of MI radius with the extent of compositional drift may be interpreted to mean that the pressure differential between the pressurized MI and the plagioclase host plays an important role in the observed compositional drift.

The observed drift in MI composition leads to the question of the source of the components. For example, $\mathrm{MgO}$ in the MI increases as a function of experimental run time and is correlated with the development of the $\mathrm{MgO}$ depletion zone in the plagioclase host for run times of 4 and 8 days. Based on the absence of such depletion in the high pressure experiments, we attribute this behavior to crystal relaxation driven by the internal pressure within the $\mathrm{MI}$, which causes a change in the partitioning behavior of $\mathrm{Mg}$. The observed trend of decreasing $\mathrm{MI} \mathrm{Al}_{2} \mathrm{O}_{3}$ and $\mathrm{Na}_{2} \mathrm{O}$ paired with increasing $\mathrm{SiO}_{2}$ and $\mathrm{MgO}$ (Figure 1) is inconsistent with the addition or subtraction of a feldspar component (e.g. the MIs are not on a plagioclase control line).

\section{CONCLUSION}

To interpret information from MIs it is important to assess how post-entrapment processes, and the methodology that we apply to remove their effects may influence our understanding of the magmatic evolution of the systems of interest. Time, temperature, pressure, host composition, and MI size all need to be considered while interpreting data from homogenized MIs. Longer homogenization run times (up to 8 days), correlate with progressive changes in MI composition. Those observations of composition drift cannot be attributed to the addition of plagioclase components as this is not evident in the trends of decreasing $\mathrm{Na}_{2} \mathrm{O}$ and increasing $\mathrm{SiO}_{2}$ and $\mathrm{MgO}$. While these findings suggest that experiments should be completed at the pressure of entrapment, in our case $30 \mathrm{~min}$ low pressure experiments were the most effective method as they are long enough to remove post-entrapment crystallization yet are short enough to prevent diffusive exchange with the host. Longer homogenization times cause drift in both the Juan de Fuca and Blanco Fracture Zone samples. Thus, the controlling process is not dependent on the plagioclase composition. However, it is important to have caution when homogenizing different compositions (different An-content of plagioclase megacrysts) at the same temperature. It is likely that this will lead to over or underheating, thus showing different results for specific major and trace elements. While certain trace elements showed weak compositional drift, the incompatible elements such as $\mathrm{Zr}, \mathrm{Nb}$ and compatible element $\mathrm{Sr}$ showed heterogeneity despite the homogenization process. This suggests that the heterogeneity is a primary signal possibly caused by local disequilibrium or trace element compatibility (Cottrell et al., 2002). When analyzing homogenized MIs, we found that the most accurate results will be obtained from small inclusions pending the analysis type. Small inclusions are more difficult to accurately measure trace elements in as the beam size is often too large.

Further work at a range of experimental pressures as well as on other samples contain crystals formed as a range of entrapment pressures is necessary to broaden our understanding of the influence of confining pressure. Homogenization is a deceptively complex process; a number of parameters such as heating rate, pressure of entrapment, extent of post-entrapment crystallization, volatile content, heating time, size of MI, location of MI within the host and others need to be assessed and understood in order to re-create the composition that represents the composition of the melt at the time of entrapment. Here we have developed a methodology effective in removing post-entrapment processes and minimizing compositional drift during MI homogenization in plagioclase. This methodology will be critical in assessing the compositions of the array of magmas forming at depth that can be used as proxies for understanding mantle processes.

Based on our results, MI up to 500 microns in diameter will homogenize in $30 \mathrm{~min}$ or less. Further, there is no evidence that the concentration of highly incompatible elements $(\mathrm{D}<0.01$ e.g. $\mathrm{Zr}, \mathrm{Nb}$ ) in MI will be changed by homogenization. They therefore are most likely to represent the composition of the magmas present at depth. Elements characterized by higher rates of 
diffusion in plagioclase (e.g. $\mathrm{Mg}, \mathrm{Sr}, \mathrm{Ba}$ ) may exhibit narrower ranges in composition due to diffusive exchange between the MI and host. If rapid quench is possible, and the entrapment pressure can be approximated, homogenization at that pressure is ideal. However, our experience suggests that homogenization at high pressure results in more issues than it solves-including inadequate quench speed, crushing of the crystal, and difficulty in assessing the temperature at which daughter crystals melt as well as the pressure of entrapment. Therefore, we recommend homogenization for short times ( $\sim 30 \mathrm{~min})$ at low pressure for basaltic systems. In assessing results from MI, it is important to note that the compositional changes correlated with experimental run time described here are relevant to any natural system where the crystals have been moved from their place of origin. Storage of crystals formed at high pressure in a shallow reservoir will be subjected to the same composition effects we describe here from controlled experiments.

\section{DATA AVAILABILITY STATEMENT}

The original contributions presented in the study are included in the article. EMP and LA-ICP-MS data of the phases from all run products are provided under Supplementary Material. Further inquiries can be directed to the corresponding author.

\section{AUTHOR CONTRIBUTIONS}

This work was carried out by M.Sc. KL under the guidance of major thesis advisor GU as part of her thesis research. RLN provided constant intellectual support during the process. The homogenization experiments, sample preparation, and polishing

\section{REFERENCES}

Adams, D. T., Nielsen, R. L., Kent, A. J., and Tepley, F. J. (2011). Origin of minor and trace element compositional diversity in anorthitic feldspar phenocrysts and melt inclusions from the Juan de Fuca Ridge. Geochem. Geophys. Geosy. 12, 12. doi:10.1029/2011GC003778

Anderson, A. T., and Wright, T. L. (1972). Phenocrysts and glass inclusions and their bearing on oxidation and mixing of basaltic magmas, Kilauea Volcano, Hawaii. Am. Mineral. 57, 188-216.

Bennett, E. N., Jenner, F. E., Millet, M. A., Cashman, K. V., and Lissenberg, C. J. (2019). Deep roots for mid-ocean-ridge volcanoes revealed by plagioclasehosted melt inclusions. Nature 572 (7768), 235-239. doi:10.1038/s41586-0191448-0

Bindeman, I. N., Davis, A. M., and Drake, M. J. (1998). Ion microprobe study of plagioclase-basalt partition experiments at natural concentration levels of trace elements. Geochem. Cosmochim. Acta. 62, 1175-1193.

Blundy, J. D., and Wood, B. J. (1991). Crystal-chemical controls on the partitioning of $\mathrm{Sr}$ and $\mathrm{Ba}$ between plagioclase feldspar, silicate melts, and hydrothermal fluids. Geochem. Cosmochim. Acta. 55, 193-209.

Bryan, W. B. (1983). Systematics of modal phenocryst assemblages in submarine basalts: petrologic implications. Contrib. Mineral. Petrol. 83 (1), 62-74.

Cherniak, D. J., and Watson, E. B. (2020). Ti diffusion in feldspar. Am. Mineral. 105, 1040-1050. doi:10.2138/am-2020-7272

Coogan, L. A. (2014). The lower oceanic crust, treatise on geochemistry. 2nd ed. Victoria, Canada: University of VictoriaElsevier Press, 497-541. were carried out by KL at SDSM\&T in GU's laboratory where she is trained by GU to do the experiments. High pressure homogenization experiments were done by David Walker at Lamont Doherty Earth Observatory (LDEO) and prepped by $\mathrm{KL}$ with the help of GU who is a research associate at AMNH/ LDEO. Analytical protocols for LA-ICP-MS and EMP and analysis were completed at Oregon State University by KL under the guidance of RN, GU, Frank Tepley and Chris Russo. RLN and GU accompanied to KL during EMPA visits for help with data collection. Data interpretation and composure of manuscript was done by KL under the advice and editing of GU and RLN.

\section{FUNDING}

Support for this work was provided by the National Science Foundation under grant number OCE-1634206 and OCE-163421 to RLN together with the NASA South Dakota Space Consortium grant to KL and SD Board of Reagents grant (441946, MA2000006) to GU.

\section{ACKNOWLEDGMENTS}

The authors thank M. A. Longpré, T. Kuritani, J. Coumans, and two anonymous reviewer for detailed and thoughtful input that greatly helped to improve the quality and clarity of the manuscript. The authors are also grateful to $M$. A. Longpré for the editorial handling of this manuscript. Authors would also like to acknowledge the scientific input and laboratory assistance from David Walker, Frank Tepley, and Chris Russo.

Cottrell, E., Spiegelman, M., and Langmuir, C. H. (2002). Consequences of diffusive reequilibration for the interpretation of melt inclusions. Geochem. Geophys. Geosy. 3 (4), 1-26. doi:10.1029/2002GC000502

Coumans, J. P., Stix, J., Clague, D. A., Minarik, W. G., and Layne, G. D. (2016). Melt-rock interaction near the Moho: evidence from crystal cargo in lavas from near-ridge seamounts. Geochem. Cosmochim. Acta. 191, 139-164. doi:10.1002/ 2016GL071327

Danyushevsky, L. V., Della-Pasqua, F. N., and Sokolov, S. (2000). Re-equilibration of melt inclusions trapped by magnesian olivine phenocrysts from subductionrelated magmas: petrological implications. Contrib. Mineral. Petrol. 138 (1-2), 68-83. doi:10.1007/pl00007664

Danyushevsky, L. V., McNeill, A. W., and Sobolev, A. V. (2002). Experimental and petrological studies of melt inclusions in phenocrysts from mantle-derived magmas: an overview of techniques, advantages, and complications. Chem. Geol. 183 (1), 5-24. doi:10.1016/S0009-2541(01)00369-2

Dohmen, R., and Blundy, J. (2014). A predictive thermodynamic model for element partitioning between plagioclase and melt as a function of pressure, temperature, and composition. Am. J. Sci. 314 (9), 1319-1372. doi:10.2475/ 09.2014 .04

Drignon, M. J., Nielsen, R. L., Tepley, F. J., III, and Bodnar, R. J. (2019). Reequilibration processes occurring in plagioclase-hosted melt inclusions from Plagioclase Ultraphyric Basalts. Geochem. Geophys. Geosy. 20, 109-119. doi:10. 46427/gold2020.1468

Drignon, M. J., Nielsen, R. L., Tepley, F. J., III, and Bodnar, R. J. (2018). Upper mantle origin of plagioclase megacrysts from plagioclase-ultraphyric midoceanic ridge basalt. Geol. 47 (1), 43-46. doi:10.1130/g45542.1 
Dungan, M. A., and Rhodes, J. M. (1978). Residual glasses and melt inclusions in basalts from DSDP Legs 45 and 46: evidence for magma mixing. Contrib. Mineral. Petrol. 67 (4), 417-431.

Dygert, N., Draper, D. S., Rapp, J. F., Lapen, T. J., Fagan, A. L., and Neal, C. R. (2020). Experimental determinations of trace element partitioning between plagioclase, pigeonite, olivine, and lunar basaltic melts and an $\mathrm{fO}_{2}$ dependent model for plagioclase-melt Eu partitioning. Geochem. Cosmochim. Acta. 279, 25-280. doi:10.1111/bre.12373

Ferriss, E., Plank, T., Newcombe, M., Walker, D., and Hauri, E. (2018). Rates of dehydration of olivines from San Carlos and Kilauea Iki. Geochem. Cosmochim. Acta. 242, 1017. doi:10.1016/j.gca.2018.08.050

Fram, M. S., and Longhi, J. (1992). Phase equilibria of dikes associated with Proterozoic anorthosite complexes. Am. Mineral. 77, 605-616.

Gaetani, G. A., O'Leary, J. A., Shimizu, N., Bucholz, C. E., and Newville, M. (2012). Rapid reequilibration of $\mathrm{H}_{2} \mathrm{O}$ and oxygen fugacity in olivine-hosted melt inclusions. Geol. 40 (10), 915-918. doi:10.1130/g32992.1

Ghiorso, M. S., and Gualda, G. A. (2015). An $\mathrm{H}_{2} \mathrm{O}-\mathrm{CO}_{2}$ mixed fluid saturation model compatible with rhyolite-MELTS. Contrib. Mineral. Petrol. 169, 6. doi:10.1007/s00410-015-1141-8

Ghiorso, M. S., Hirschmann, M. M., Reiners, P. W., and Kress, V. C., III (2002). The pMELTS: a revision of MELTS for improved calculation of phase relations and major element partitioning related to partial melting of the mantle to $3 \mathrm{GPa}$. Geochem. Geophys. Geosy. 3, 5. doi:10.1029/2001GC000217

Kent, A. J., and Putirka, K. D., (2008). "Melt inclusions in basaltic and related volcanic rocksIII" in Reviews in mineralogy and geochemistry (Washington, D.C.: Geochemical Society Press), 273-331.

Kohut, E., and Nielsen, R. L. (2004). Melt inclusion formation mechanisms and compositional effects in high-An feldspar and high-Fo olivine in anhydrous mafic silicate liquids. Contrib. Mineral. Petrol. 147 (6), 684-704. doi:10.1007/ s00410-004-0576-0

Kotash, A., Tepley, F. J., III, Nielsen, R., and Bodnar, R. J. (2019). $\mathrm{CO}_{2}$ and $\mathrm{H}_{2} \mathrm{O}$ in plagioclase-hosted melt inclusions from ocean-ridge lavas: an indicator of crystallization in the lower oceanic crust. Abstract retrieved from AGU Fall Meeting. (Abstract No. V13C-0172).

Lange, A. E., Nielsen, R. L., Tepley, F. J., III, and Kent, A. J. (2013a). The petrogenesis of plagioclase-phyric basalts at mid-ocean ridges. Geochem. Geophys. Geosy. 14, 8. doi:10.1002/ggge.20207

Lange, A. E., Nielsen, R. L., Tepley, F. J., III, and Kent, A. J. (2013b). Diverse Sr isotope signatures preserved in mid-oceanic-ridge basalt plagioclase. Geology 41 (2), 279-282. doi:10.1016/j.chemgeo.2020.119566

Langmuir, C. H. (1989). Geochemical consequences of in situ crystallization. Nature 340 (6230), 199-205.

Le Voyer, M., Kelley, K. A., Cottrell, E., and Hauri, E. H. (2017). Heterogeneity in mantle carbon content from $\mathrm{CO}_{2}$-undersaturated basalts. Nat. Commun. 8, 1 . doi:10.1038/ncomms 14062

Lissenberg, C. J., and MacLeod, C. J. (2016). A reactive porous flow control on midocean ridge magmatic evolution. J. Petrol. 57 (11), 2195-2220. doi:10.1093/ petrology/egw074

Maclennan, J. (2008). Concurrent mixing and cooling of melts under Iceland. J. Petrol. 49 (11), 1931-1953. doi:10.1093/petrology/egn052

Michael, P. J., and Schilling, J. G. (1989). Chlorine in mid-ocean ridge magmas: evidence for assimilation of seawater-influenced components. Geochem. Cosmochim. Acta. 53 (12), 3131-3143.

Neave, D. A., Hartley, M. E., Maclennan, J., Edmonds, M., and Thordarson, T. (2017). Volatile and light lithophile elements in high-anorthite plagioclasehosted melt inclusions from Iceland. Geochem. Cosmochim. Acta 205, 100-118.

Nielsen, R. L., Crum, J., Bourgeois, R., Hascall, K., Forsythe, L. M., Fisk, M. R., et al. (1995). Melt inclusions in high-An plagioclase from the Gorda Ridge: an example of the local diversity of MORB parent magmas. Contrib. Mineral. Petrol. 122, 34-50.

Nielsen, R. L., Michael, P. J., and Sours-Page, R. (1998). Chemical and physical indicators of compromised melt inclusions. Geochem. Cosmochim. Acta. 62 (5), 831-839.
Nielsen, R. L. (2011). The effects of re-homogenization on plagioclase-hosted melt inclusions. Geochem. Geophys. Geosyst. 12, 10. doi:10.1029/2011GC003822

Nielsen, R. L., Ustunisik, G., Lange, A. E., Tepley, F. J., III, and Kent, A. J. R. (2020). Trace element and isotopic characteristics of plagioclase megacrysts in plagioclase ultraphyric basalts (PUBs). Geochem. Geophys. Geosyst. 21. doi:10.1029/2019GC00863

Nielsen, R. L., Ustunisik, G., Weinsteiger, A. B., Tepley, F. J., Johnston, A. D., and Kent, A. J. (2017). Trace element partitioning between plagioclase and melt: an investigation of the impact of experimental and analytical procedures. Geochem. Geophys. Geosyst. 18, 3359-3384. doi:10.1002/2017GC007080

O'Hara, M. J. (1977). Geochemical evolution during fractional crystallization of a periodically refilled magma chamber. Nature 266 (5602), 503-507.

O'Neill, H. S. C., and Jenner, F. E. (2016). Causes of the compositional variability among ocean floor basalts. J. Petrol. 57 (11), 2163-2194. doi:10.1016/j.epsl.2018. 10.002

Roedder, E. (1979). Origin and significance of magmatic inclusions. Bull. Mineral. $102(5), 487-510$.

Rubin, K. H., Sinton, J. M., Maclennan, J., and Hellebrand, E. (2009). Magmatic filtering of mantle compositions at mid-ocean-ridge volcanoes. Nat. GeoSci. 2 (5), 321-328. doi:10.1038/NGEO504

Schiavi, F., Provost, A., Schiano, P., and Cluzel, N. (2016). P-V-T-X evolution of olivine-hosted melt inclusions during high-temperature homogenization treatment. Geochem. Cosmochim. Acta. 172, 1-21. doi:10.1038/NGEO504

Shorttle, O., Moussallam, Y., Hartley, M. E., Maclennan, J., Edmonds, M., and Murton, B. J. (2015). Fe-XANES analyses of Reykjanes Ridge basalts: implications for oceanic crust's role in the solid Earth oxygen cycle. Earth Planet Sci. Lett. 427, 272-285. doi:10.1016/j.epsl.2015.07.017

Sinton, C. W., Christie, D. M., Coombs, V. L., Nielsen, R. L., and Fisk, M. R. (1993). Near-primary melt inclusions in anorthite phenocrysts from the Galapagos Platform. Earth Planet Sci. Lett. 119 (4), 527-537.

Sobolev, A. V. (1996). Melt inclusions in minerals as a source of principle petrological information. Petrol. 4 (3), 209-220.

Sobolev, A. V., and Shimizu, N. (1993). Ultra-depleted primary melt included in an olivine from the Mid-Atlantic ridge. Nature 363, 151-154.

Sours-Page, R., Johnson, K. T., Nielsen, R. L., and Karsten, J. L. (1999). Local and regional variation of MORB parent magmas: evidence from melt inclusions from the endeavour segment of the Juan de Fuca Ridge. Contrib. Mineral. Petrol. 134 (4), 342-363.

Tait, S. (1992). Selective preservation of melt inclusions in igneous phenocrysts. Am. Mineral. 77 (1), 146-155.

Ustunisik, G., Nielsen, R. L., and Walker, D. (2020). The missing magmas of MOR.Abstract retrieved from Goldschmidt Conference. (Goldschmidt2020 Abstract).

Wallace, P., and Carmichael, I. S. (1992). Sulfur in basaltic magmas. Geochem. Cosmochim. Acta. 56 (5), 1863-1874.

Wanless, V. D., and Shaw, A. M. (2012). Lower crustal crystallization and melt evolution at mid-ocean ridges. Nat. GeoSci. 5 (9), 651. doi:10.1186/1880-5981-66-81

Zhang, Y. (1998). Mechanical and phase equilibria in inclusion-host systems. Earth Planet Sci. Lett. 157 (3), 209-222.

Conflict of Interest: The authors declare that Frank Tepley (OSU), Adam Kent (OSU), Hanna Nekvasil (Stony Brook), David Walker (LDEO of Columbia University), Denton Ebel (AMNH), Francis McCubbin (NASA JSC) are the most recent collaborators of co-authors and review of this article by them could be considered as a potential conflict of interest.

Copyright () 2021 Lewis, Ustunisik and Nielsen. This is an open-access article distributed under the terms of the Creative Commons Attribution License (CC BY). The use, distribution or reproduction in other forums is permitted, provided the original author(s) and the copyright owner(s) are credited and that the original publication in this journal is cited, in accordance with accepted academic practice. No use, distribution or reproduction is permitted which does not comply with these terms. 